\title{
The Northwestern Argentinean Low: A Study of Two Typical Events
}

\author{
MARCElo E. Seluchi \\ Centro de Previsão de Tempo e Estudos Climáticos/INPE, Cachoeira Paulista, Sao Paulo, Brazil
}

\section{A. Celeste Saulo and Matilde Nicolini}

Centro de Investigaciones del Mar y la Atmósfera, Departamento de Ciencias de la Atmósfera y los Océanos, University of Buenos Aires, Buenos Aires, Argentina

PRAKKi SATYAMURTY

Centro de Previsão de Tempo e Estudos Climáticos/INPE, Cachoeira Paulista, Sao Paulo, Brazil

(Manuscript received 20 May 2002, in final form 31 March 2003)

\section{ABSTRACT}

\begin{abstract}
A low pressure system [known as the northwestern Argentinean low (NAL)] is commonly observed over northwestern Argentina near the Andean slopes. This study describes two NAL episodes for summer and winter, with emphasis on the characterization of their three-dimensional structure and temporal variability. With the aid of a high-resolution regional model [Eta/Centro de Previsão de Tempo e Estudos Climáticos (CPTEC)], the main mechanisms involved in the NAL life cycle were studied in order to examine how the thermal topographical processes influenced the system behavior.

Surface pressure changes in the NAL are mostly dominated by the 600-900-hPa thickness variability, suggesting its thermal character. Based on this result, the temperature tendency equation has been used to quantify all the contributions to thermal changes.

The summer NAL has a significant diurnal cycle that has been dominated by surface warming. This single mechanism can explain the low pressure system formation by itself, suggesting that the NAL could always be present during this season unless an adverse process counteracts the positive contribution by the surface sensible heat flux. Other favoring processes found in the analyzed cases were the Foehn effect (warming by subsidence) and the latent heat release. The intermittent behavior of the NAL is associated with a suppression of net warming in the 600-900-hPa layer, due to a cold-air outbreak.

In the winter case, the Foehn effect has been mainly responsible for the NAL development. This mechanism acts in connection with an upper-level cyclonic disturbance approaching the Andes, indicating that the thermal response is triggered by a dynamical forcing. As the Foehn effect (locally known as Zonda wind) is a frequent winter phenomenon, the NAL intermittence during this season could be related to transient baroclinic activity, which modulates both the intensification and the decay stages.

The NAL has been regarded as a thermal-orographic system. This study suggests that the analyzed NALs behave as an almost "pure" surface thermally driven low in summer, while dynamical-orographic forcing is the organizing mechanism in winter.
\end{abstract}

\section{Introduction}

During austral summer an upper-level (300 hPa) anticyclonic circulation (the Bolivian high), whose origin has been related to latent heat release produced by convection, appears over the South American continent (Figueroa et al. 1995, Lenters and Cook 1997). In light of the thermal origin of this anticyclone, it should be associated with a quasi-permanent low pressure system

Corresponding author address: Marcelo E. Seluchi, Centro de Previsão de Tempo e Estudos Climáticos (CPTEC)/INPE, Rodovia Dutra Km 39, 12630-000 Cachoeira Paulista, Sao Paulo, Brazil. E-mail: seluchi@cptec.inpe.br near the surface (Schwerdtfeger 1976) that is also driven by continental heating (Alessandro 1993). This surface system, known as the Chaco low, is located over the Chaco region (between Paraguay and Bolivia) but extends meridionally on the lee side of the Andes, from the Amazon to northwestern Argentina.

Detailed maps of surface pressure analysis (Hoffmann 1975) show that this low pressure zone exhibits two separated centers. The first one [which we will designate as the Chaco low (CHL)] is located over the Chaco region, and the second one [which we will call the Northwestern Argentinean Low, NAL) is placed in northwestern Argentina. Despite the fact that both centers seem to belong to a single cyclonic system, some 
differences in their behavior can be recognized, summarized as follows:

1) The CHL is situated in a region of heavy annual rainfall (around $1500 \mathrm{~mm} \mathrm{yr}^{-1}$ ). In contrast, precipitation amounts are lower than $300 \mathrm{~mm} \mathrm{yr}^{-1}$ over northwestern Argentina.

2) The CHL is associated with an anticyclonic system at upper levels that gradually disappears toward the NAL region, south of the tropic of Capricorn.

3) Both systems attain similar sea level pressure; however, daily pressure variability to the east of the Andes increases southward (Seluchi and Marengo 2000). This fact suggests that while the CHL has a quasi-permanent behavior, the NAL located farther south is rather intermittent.

4) During winter the CHL is practically absent, whereas the NAL, though quite intermittent, is still present in the lower troposphere.

This dissimilar behavior suggests that different dynamic and/or thermodynamic mechanisms may contribute to the maintenance of each low pressure center. Consequently, it is of interest to analyze the mechanisms responsible for the NAL life cycle.

Studies of the NAL have rarely been published in the literature. Schwerdtfeger (1954) identified a "thermal" low characteristic of the summer pressure pattern of northwestern Argentina. He found that this system is shallow (it disappears at the 700-hPa level) and exhibits considerable influence on the wind regime in the lower layers as well as on the formation of summer precipitation in the Argentinean plains. Schwerdtfeger indicated that this depression disappears after a cold-air eruption, emphasizing that the weakening periods are shorter than the intensification stages.

Lichtenstein (1980, hereafter L80) used climatological maps and daily data from a single year (1967) to perform the most comprehensive work related to the NAL (at least to the authors' knowledge). According to L80, the mean position of the NAL is around $30^{\circ} \mathrm{S}$ and east of the Andes mountain range, near La Rioja station (around $66^{\circ} \mathrm{W}$; denoted LR in Fig. 1). Although the mean position of the NAL is near $30^{\circ} \mathrm{S}$, it has a relatively high latitudinal variability, while its longitudinal location is less variable and about $300 \mathrm{~km}$ to the east of the Andean slopes. This region is characterized by low precipitation that occurs mainly during the warm season. Farther to the east, precipitation gradually increases, while its seasonal variability becomes reduced (González and Barros 1996; Montecinos et al. 2000). The geography surrounding the NAL is dominated by the Andes (Fig. 1), which attain a mean altitude of around $4000-5000 \mathrm{~m}$ between $33^{\circ} \mathrm{S}$ and the equator. North of $33^{\circ} \mathrm{S}$, the Andes gradually widen, forming the PeruvianBolivian plateau centered around $20^{\circ} \mathrm{S}$.

The main findings of L80 indicate that the NAL is usually more intense and persistent during summer. Its existence is diabatically driven, since higher tempera-

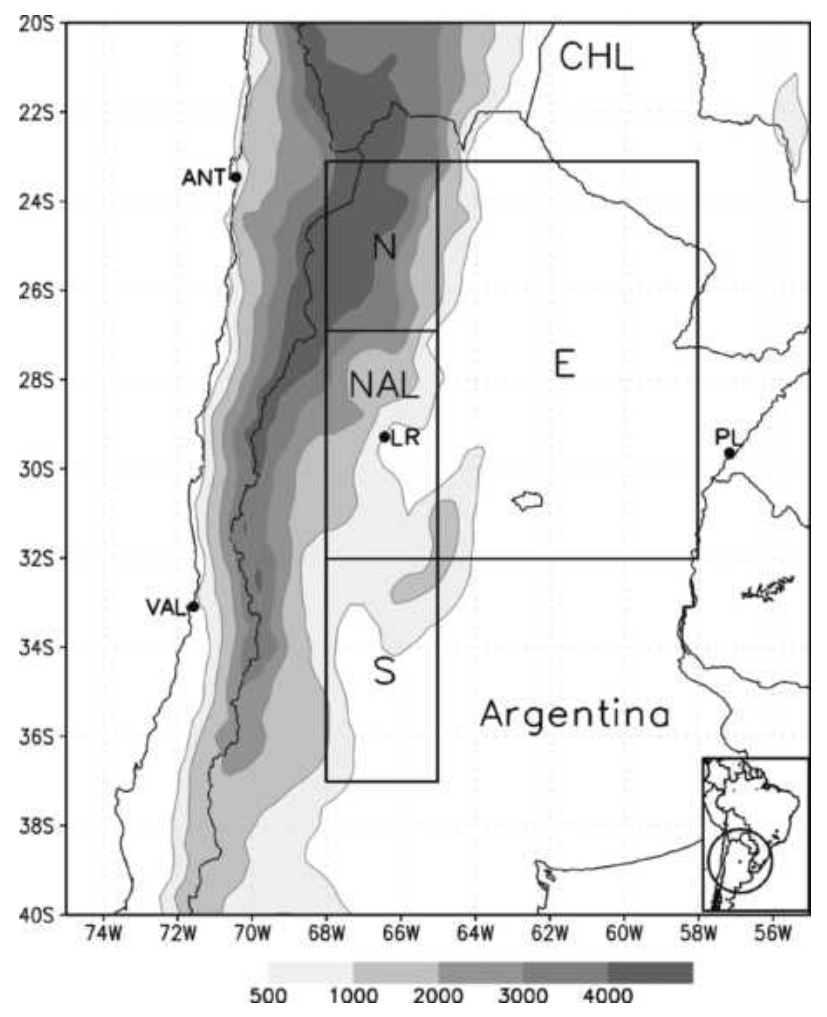

FIG. 1. Map of the region under study, including topography (elevations higher than $500 \mathrm{~m}$ are shaded) and location of some of the meteorological stations used [Valparaíso (VAL), Antofagasta (ANT) Paso de los Libres (PL), and La Rioja (LR)]. Also shown are the approximate mean annual locations of the northwest Argentinaean Low (NAL), the Chaco low (CHL), and the boxes of study north (N), east $(E)$, and south (S) of the NAL location.

tures are found in the lower troposphere, with respect to the surrounding regions. This low pressure system usually disappears above the $500-\mathrm{hPa}$ level, although a compensating anticyclonic circulation is not evident at the upper levels, at least in climatological maps. The NAL is a zonally asymmetric depression with a stronger pressure gradient to the west. Lichtenstein defined an index to measure its intensity that we will call the Lichtenstein index, denoted by $I_{L}$ :

$$
I_{L}=0.5\left[0.5\left(P_{\mathrm{ANT}}+P_{\mathrm{VAL}}\right)+P_{\mathrm{PL}}\right]-P_{\mathrm{LR}},
$$

where $P_{\mathrm{ANT}}$ is the sea level pressure at Antofagasta $\left(23^{\circ} \mathrm{S}, 70^{\circ} \mathrm{W}\right), P_{\mathrm{VAL}}$ at Valparaiso $\left(33^{\circ} \mathrm{S}, 71^{\circ} \mathrm{W}\right), P_{\mathrm{PL}}$ at Paso de los Libres $\left(29^{\circ} \mathrm{S}, 57^{\circ} \mathrm{W}\right)$, and $P_{\mathrm{LR}}$ at La Rioja $\left(29^{\circ} \mathrm{S}, 66^{\circ} \mathrm{W}\right)$. See Fig. 1 for the station locations. The $I_{L}$ is essentially a finite difference for the second derivative of pressure in the $x$ direction and, as such, should be proportional to the geostrophic vorticity.

Through the analysis of climatological maps, L80 established that the average value of the $I_{L}$ is $3.1 \mathrm{hPa}$ and its standard deviation is $4.7 \mathrm{hPa}$. The maximum monthly mean intensity of the NAL is observed in December $\left(I_{L}\right.$ $=6.9 \mathrm{hPa})$ and the minimum in June $\left(I_{L}=2.2 \mathrm{hPa}\right)$. Lichtenstein used this index as a key parameter to iden- 
tify particular NAL cases and analyze their possible physical causes. He identified the positive surface heat balance as an important mechanism during summer, since it alone proved to be capable of explaining the existence of a thermal low in northwestern Argentina. He also stated that this process could not completely justify the magnitude of the low pressure center, even in summer. The other mechanism suggested by L80 that could determine the intensity and the intermittent behavior in summer and could be the primary contributing process in winter is the horizontal warm advection. This warm advection could be favored by the Andes through a channeling effect on northerly winds prior to the passage of a migratory disturbance (Gan and Rao 1994; Garreaud and Wallace 1998). Because of limitations in the observational network, L80 calculated this advection near $63^{\circ} \mathrm{W}$, that is, about $500-600 \mathrm{~km}$ to the east of the NAL center. Lichtenstein proposed the forced subsidence leeward of the Andes as another possible mechanism of the surface low pressure formation. Although this mechanism could not be quantified, because of the lack of sounding data over the NAL region, L80 indirectly evaluated this contribution through the correlation between the $I_{L}$ and the zonal component of the wind near the crest of the Andes, without obtaining statistical significance. Finally, he demonstrated the existence of a statistical relationship between the intensity of the NAL and precipitating systems occurring over northeastern Argentina, southern Brazil, and Uruguay, which also suggests the importance of the NAL in driving moisture into the aforementioned region.

Lichtenstein's work can be considered pioneering since it addresses for the first time the analysis of NAL vertical structure, physical processes taking place, and possible relationships with other significant weather phenomena. Nevertheless, because of observational and technical limitations it was not possible for L80 to study the NAL's three-dimensional structure at a regional scale. Accordingly, physical causes could be investigated only in a qualitative way, through indirect variables or quantifying processes outside the area encompassed by the NAL. Besides this valuable observational work, neither numerical simulation nor gridded-datasetbased studies of the NAL have been reported so far.

The goal of this study is to examine two "typical" cases of NAL that occurred in summer and winter, respectively. These events were chosen after analyzing their intensity, duration, and associated synoptic pattern. Particular emphasis is given to the processes responsible for the NAL deepening and decaying stages, through the analysis of numerical simulations using a regional model. Because of the thermal nature of the system, this article also undertakes the study of the diurnal variability. The work is organized as follows: Model characteristics and methodology are presented in section 2 ; the selected NAL events are described in section 3; and physical mechanisms acting upon these events are dis- cussed in section 4. Finally, the concluding remarks are presented in section 5 .

\section{Model description and methodology}

The Eta Regional Model at the Centro de Previsão de Tempo e Estudos Climáticos (Eta/CPTEC) has been used operationally at the Brazilian Center for Weather Forecasts and Climate Studies to provide weather forecasts over most of South America since late 1996. The Eta/CPTEC is a hydrostatic regional model that uses the eta vertical coordinate, defined by Mesinger (1984). The eta coordinate is a generalization of the sigma coordinate. Although both of them are pressure based and normalized from 0 to 1 , eta is normalized with respect to sea level pressure, whereas sigma is normalized with respect to surface pressure. The advantage of the eta coordinate is that the resultant surfaces are practically horizontal, even on mountain slopes, allowing a better representation of the horizontal variability of the atmospheric parameters in the presence of sharp topography. Model topography is represented by steps, the tops of which coincide with the eta surfaces (step mountain orography; see Fig. 6). For this reason it is believed that this model is particularly appropriate to analyze meteorological phenomena lying near steep topography, such as the NAL.

The prognostic variables are temperature, specific humidity, winds, surface pressure, turbulent kinetic energy and cloud water. The equations are solved on the Arakawa-E grid and integrated through a split-explicit scheme based on forward-backward and Euler-backward schemes, both modified by Janjic (1979).

The Eta/CPTEC is run with a $40-\mathrm{km}$ horizontal resolution and 38 vertical layers, with the model top placed at the 25-hPa level. The model includes a complete physics package, with the Betts and Miller (1986) scheme for convective precipitation modified by Janjic (1994). Large-scale precipitation is solved in an explicit way (Zhao and Carr 1977). Turbulent fluxes are represented through an updated Mellor and Yamada 2.5order scheme. Surface heat and humidity fluxes are solved using the Monin-Obukov scheme, whereas the radiation balance (Lacis and Hansen 1974; Fels and Schwarzkopf 1975) is updated every $1 \mathrm{~h}$ of integration. The soil scheme used in the present version of the Eta/ CPTEC is the Oregon State University (OSU; Chen et al. 1996) model that includes three subsuperficial layers and another in which vegetation canopy is simulated. For more details on model physics, see Black (1994).

Initial and boundary conditions are provided by the National Centers for Environmental Prediction (NCEP) operational analyses at $6-\mathrm{h}$ intervals. Annual climatology of soil moisture, seasonal fields of albedo, and observed weekly mean sea surface temperatures are used as initial lower boundary conditions. Model domain (see Fig. 2), numerical settings, and simulation length (72 h) are the same as those implemented in the operational 


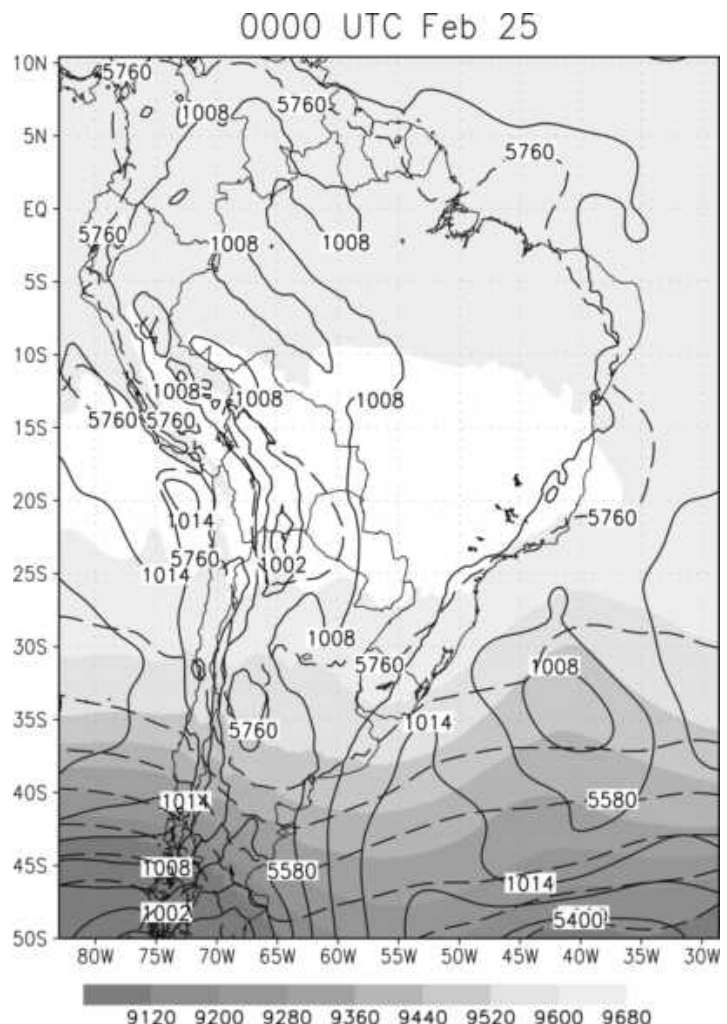

FIG. 2. Meteorological analysis corresponding to 0000 UTC $25 \mathrm{Feb}$ 2000 (initial condition for the Eta/CPTEC run provided by NCEP analysis and interpolated to the regional model domain): Sea level pressure ( $\mathrm{hPa}$, solid lines), 500-1000 hPa thickness (gpm, dashed lines), and geopotential height of the 300-hPa level (gpm, shaded).

version (Seluchi and Chou 2001). Simulated fields are obtained at intervals of $3 \mathrm{~h}$ to allow diurnal variability analysis.

Two particular cases of NAL have been chosen for the present study, one of them occurring in summer and the other in winter. The selection criteria were established as follows: Considering the intermittent behavior of the NAL, it is required that the $I_{L}$ should attain values close or superior to the corresponding monthly average of $I_{L}$ (during the active phase of the NAL). On the other hand, in order to correctly represent the system life cycle with a numerical simulation encompassing a reasonably long integration period, that is, up to 72 or $80 \mathrm{~h}$, it was required that the system life cycle not be excessively long. Finally, the selected low pressure systems should have the basic characteristics found by L80, since sometimes dynamic depressions develop over northwestern Argentina in connection with cyclogenesis on the South American coast (Seluchi and Saulo 1998). Given these conditions, the situation from 25 to 28 February 2000 was chosen to be representative of a warm-season NAL case $\left(I_{L}=5.9 \mathrm{hPa}\right)$ and the depression that occurred between 5 and 7 July $2000(L=10.0 \mathrm{hPa})$ was selected to represent a typical winter case.

The general form of the thermodynamic equation for an $\eta$ vertical coordinate presented in Mesinger et al. (1988), and used by the current Eta/CPTEC version, is

$$
\frac{\partial T}{\partial t}=-\mathbf{V} \cdot \nabla_{\eta} T-\dot{\eta} \frac{\partial T}{\partial \eta}+\frac{\chi T \omega}{p}+\frac{\dot{Q}}{C_{P}},
$$

where $T$ is temperature; $\mathbf{V}$ is the horizontal wind vector; $\omega$ is vertical velocity in pressure coordinates; $\chi$ is $R$ $\left(c_{p}\right)^{-1} ; \dot{\eta}$ is the vertical velocity in $\eta$ coordinates; and $\dot{Q} / C_{p}$ represents diabatic sources/sinks, that is, warming or cooling related to large-scale condensation, convection, radiation, surface exchanges, and friction. In this paper, the focus will be directed to the analysis of the terms of this equation. The following simplifications will be adopted for this analysis:

- The second and third terms in the rhs of (1) will be handled together, since they are due to adiabatic ascents and/or descents, and will be referred to as the "static stability" term (e.g., Bluestein 1993).

- The diabatic source/sink term will be split into three main contributions:

1) that coming from "moisture processes," which includes warming/cooling due to large-scale condensation and cumulus convection;

2) that related to "radiation," which takes into account the temperature changes associated with radiative transfers in the atmosphere; and

3 ) that encompassing "surface processes," derived from surface fluxes, which also relates to the OSU surface model previously mentioned.

This selection of terms is based on the following idea: some contributions can be analyzed together since the processes involved in their evolution are essentially the same and/or a detailed examination of their differences is beyond the scope of this paper (e.g., the relative contribution of large-scale condensation vs that coming from cumulus convection). Also, when their relative contribution is not significant, as happens with diffusive terms, they are not included in the discussion. Accordingly, the thermodynamic equation is represented, schematically, as

$$
\begin{aligned}
& \text { temperature tendency } \\
& \begin{aligned}
\approx & \text { horizontal advection }+ \text { static stability } \\
& + \text { moisture processes }+ \text { radiation } \\
& + \text { surface processes. }
\end{aligned}
\end{aligned}
$$

Terms acting in the model temperature tendency equation have been archived in order to analyze in detail the evolution of the thermal field.

The suitability of the Eta/CPTEC to represent adequately the regional features over South America has been documented in previous studies (Seluchi and Chou 2001; Saulo et al. 2000; Chou and Justi da Silva 1999). For this reason, it is assumed that the basic physical mechanisms involved in NAL may be described properly by model simulations. 


\section{Description of the 26 February and 6 July 2000 episodes}

a. Synoptic overview of the summer case and validation of the Eta/CPTEC

Because the NAL develops in a region strongly influenced by orography, with relatively coarse data coverage, NCEP reanalysis may have difficulty capturing important local features. On the other hand, the adequate horizontal and vertical resolutions of the Eta/CPTEC and its full physics package allow use of the model as a potential tool for the study of the NAL.

Figure 2 shows the sea level pressure, $300 \mathrm{hPa}$ geopotential height (shaded) and the 500-1000-hPa thickness fields (dashed) taken from the NCEP analysis as initial conditions for the summer NAL experiment that started at 0000 UTC 25 February 2000 and ended at 0000 UTC 28 February 2000. At 0000 UTC 25 February, the presence of a cold front is suggested by the thickness distribution south of $40^{\circ} \mathrm{S}$, associated with a trough approaching from the Pacific Ocean. The lowlevel trough that extends from $50^{\circ}$ to $30^{\circ} \mathrm{S}$ to the lee of the Andes defines two areas with opposite thermal advection: warm to the east and cold to the west. The low pressure center located between $37^{\circ}$ and $32^{\circ} \mathrm{S}$ is recognized as an NAL, displaced to the south of its climatological position.

Figures 3a-d display the life cycle of the NAL as depicted by the Eta/CPTEC simulation. The NAL is characterized by marked deepening during warm hours (2100 UTC, corresponding to 1800 LST) and weakening in the morning (1200 UTC). During this period the eastward movement of the upper level trough accompanies the northeastward displacement of the cold front. A warm tongue is evident from the thickness field immediately to the east of the Andes superimposed on the NAL at every analyzed time. Figure $3 d$ shows that even in the decay phase, the NAL remains within the warm air mass ahead of the baroclinic zone that follows northward frontal displacement. Figures $3 \mathrm{e}$ and $3 \mathrm{f}$ show the hand analysis at 1200 UTC 26 and 27 February, respectively, used to validate the Eta/CPTEC simulations. This time has been chosen because there is better observational-data coverage. Comparison with Figs. 3b and $3 \mathrm{~d}$ reveals that the model satisfactorily reproduces the surface pressure pattern up to $60 \mathrm{~h}$ in advance. In both cases the model slightly underestimates the depression intensity but correctly simulates its position and shape. The location of the frontal system also is accurately reproduced by the Eta/CPTEC (indicated by the maximum cyclonic curvature in the $1008-\mathrm{hPa}$ contour).

Figures $4 \mathrm{a}-\mathrm{d}$ compare the hand analyses and the Eta/ CPTEC diagnoses for the winter case (36- and 60-h simulations, respectively). Again, the model underestimates the depression intensity but satisfactorily locates the NAL and the frontal system situated farther south.

Figures $5 \mathrm{a}$ and $5 \mathrm{~b}$ show the temporal evolution of the sea level pressure observed at La Rioja station (near the center of the NAL) and that diagnosed by the Eta/ CPTEC for both summer and winter cases. In general, the model tends to underestimate the sea level pressure of maximum NAL intensity and overestimates it in the morning hours. In other words, the model slightly overestimates the amplitude of the diurnal cycle of the pressure near the center of the NAL. However, the pressure diagnosed by the model always remains close to the observations throughout the entire life cycle. Moreover, the pressure maxima and minima are accurately simulated in both cases.

In general, it can be concluded that the Eta/CPTEC reproduces with acceptable accuracy the position, shape, intensity, and evolution of the NAL. For this reason it is considered that this model is an appropriate tool to analyze the physical mechanisms involved in the NAL evolution.

\section{b. Distinct features associated with the NAL}

The vertical section of the temperature and meridional wind along $30^{\circ} \mathrm{S}$ at the moment of maximum NAL intensity for the 26 February case is illustrated in Fig. 6a. Different circulation regimes, characterized by a sign reversal in the meridional wind component (dashed), distinct temperatures, and related stability conditions, are noticed at both sides of the Andes. To the west, the subtropical Pacific anticyclone is associated with colder temperatures and more stable conditions, with stronger southerly winds near the surface, and is bounded by the subsidence inversion. In the lee of the mountains, northerly winds (shaded) are immersed in a warm and less stable air mass. Since the NAL is a quasi-permanent system, particularly in summer, those winds contribute to the intrusion of warm tropical air masses into middle latitudes. A vertical cross section at $66^{\circ} \mathrm{W}$, near the NAL location (Fig. 6b), shows that baroclinicity concentrates poleward of $33^{\circ} \mathrm{S}$ and is linked to the previously described cold front. Below the 600-hPa level, over the NAL region and over the Bolivian plateau, barotropy is more apparent, as evidenced by the less marked crossing between isotherms and isentropic lines and the weak horizontal gradient of potential temperature.

Figure 7 depicts the temporal evolution of the geopotential height at 300,600, and $900 \mathrm{hPa}$, and the 600900-hPa thickness, horizontally averaged over the area encompassed by the NAL (see Fig. 1 for the location of this box). A strong diurnal cycle at the $900 \mathrm{hPa}$ geopotential height, characterized by deepening during daytime and weakening during nighttime hours, is detected. This diurnal cycle in the NAL has not been previously documented by L80, since only data from 1200 UTC was used in that work.

The system intensification starts at 0900 UTC 25 February, and the minimum pressure is attained by 2100 UTC 26 February. After this time, the system enters a rapid decay phase. A relevant feature in this figure is the opposite behaviors of the thickness and the $900-\mathrm{hPa}$ 
(a) 2100 UTC Feb 25

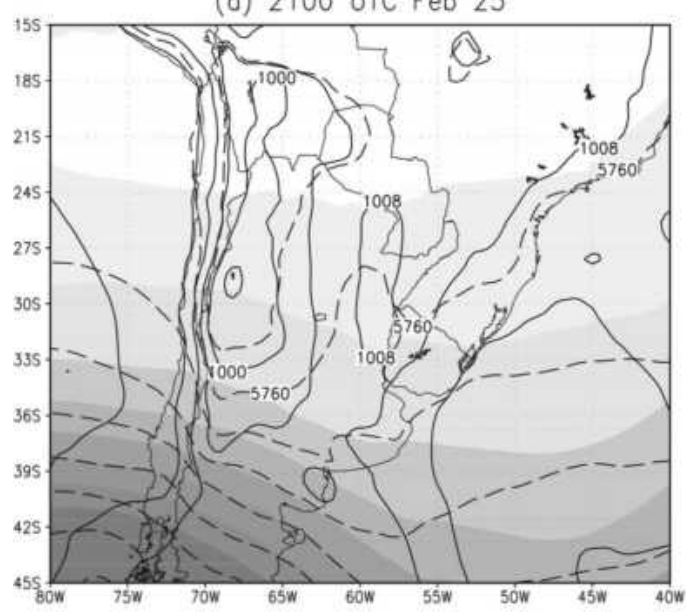

$\begin{array}{llllllll}9120 & 9200 & 9280 & 9360 & 9440 & 9520 & 9600 & 9680\end{array}$

(c) 2100 UTC Feb 26

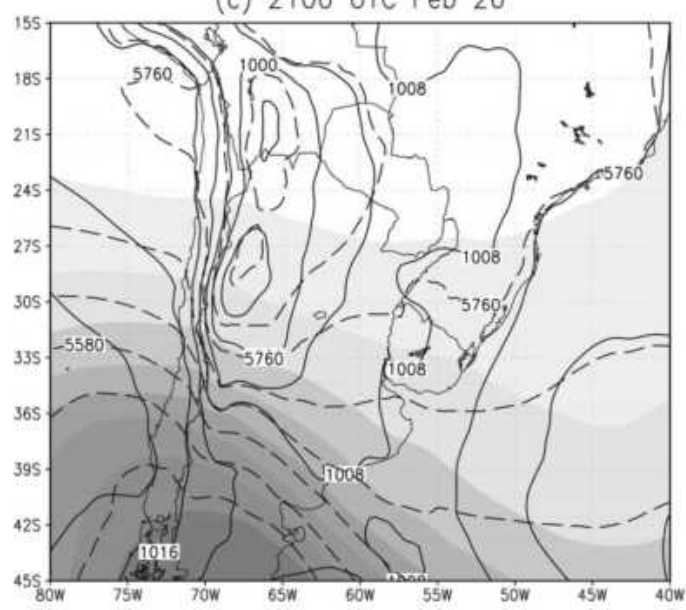

(e) 1200 UTC Feb 26

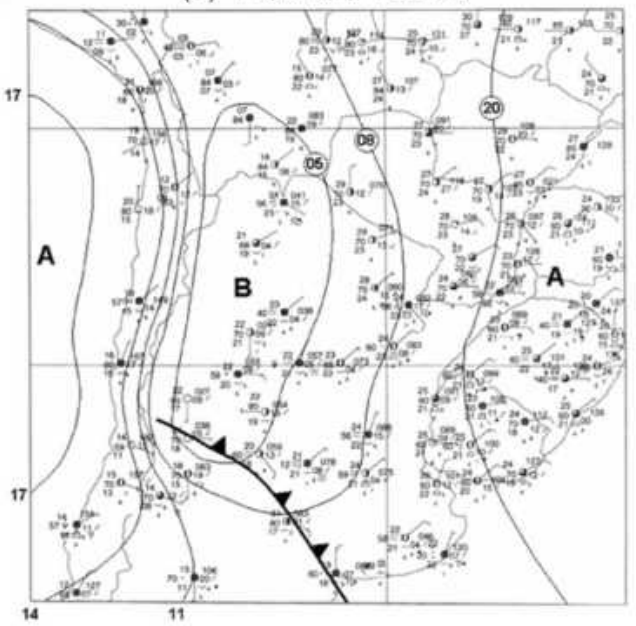

(b) 1200 UTC Feb 26

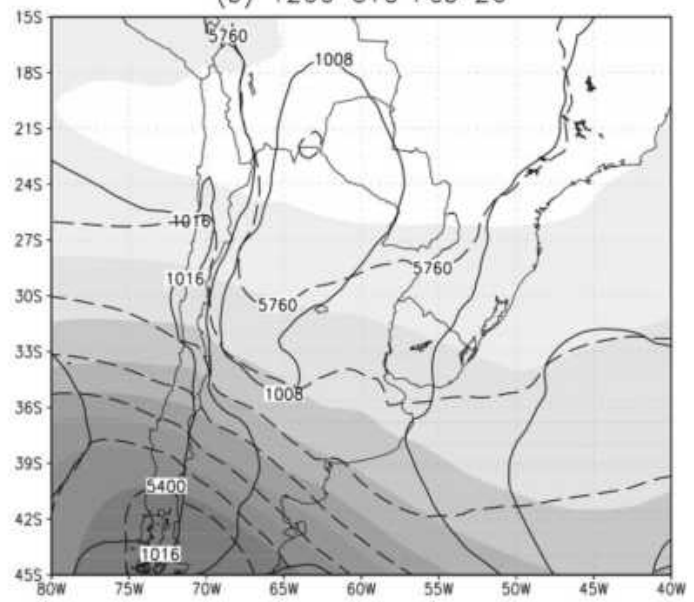

$\begin{array}{llllllll}9120 & 9200 & 9280 & 9360 & 9440 & 9520 & 9600 & 9680\end{array}$

(d) 1200 UTC Feb 27

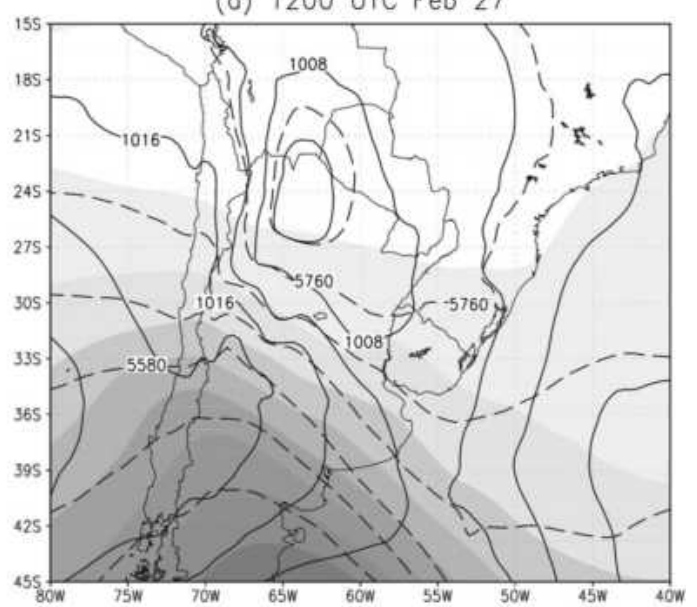

(f) 1200 UTC Feb 27

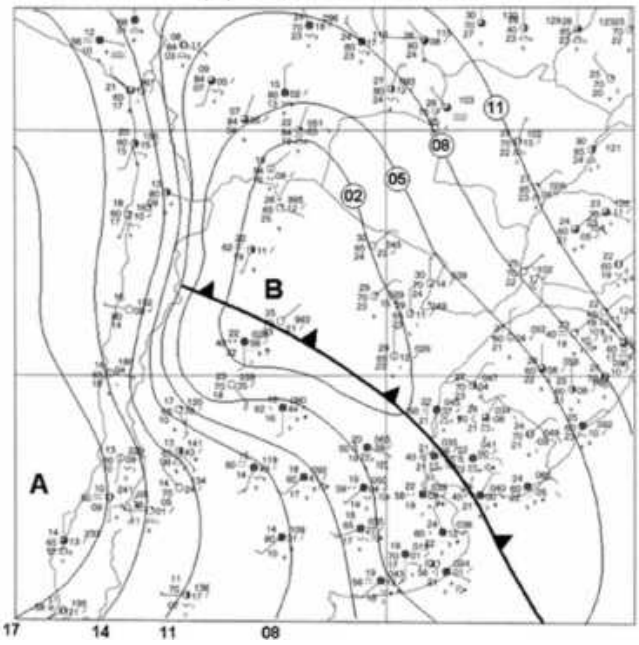


(a) 1200 UTC July 05

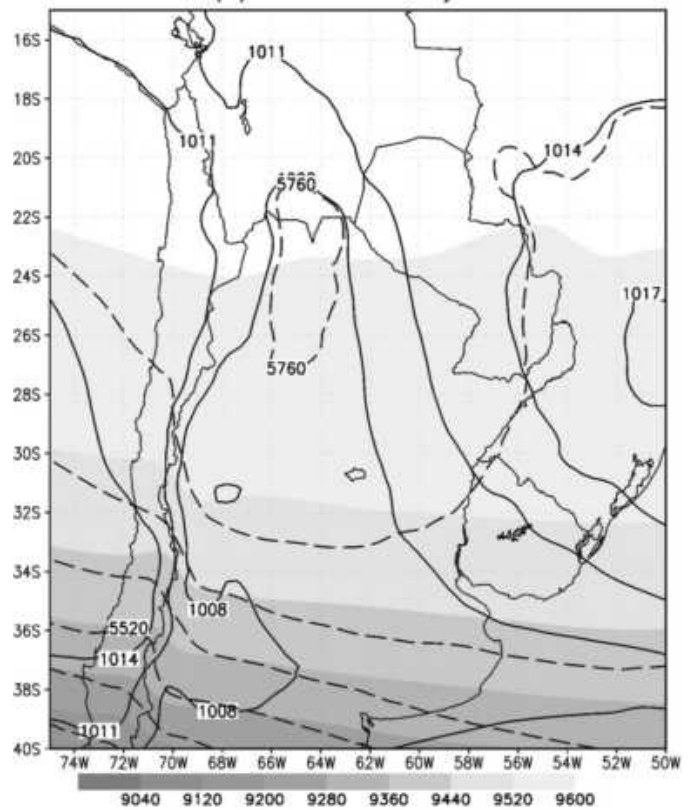

(c) 1200 UTC July 05

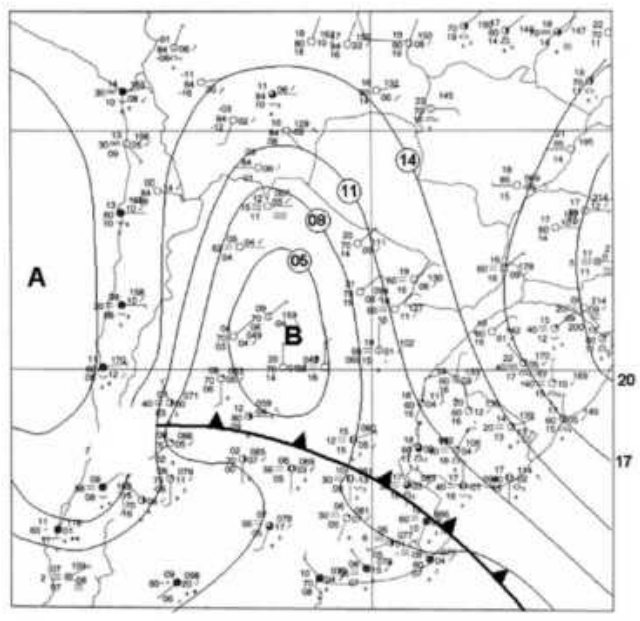

(b) 1200 UTC July 06

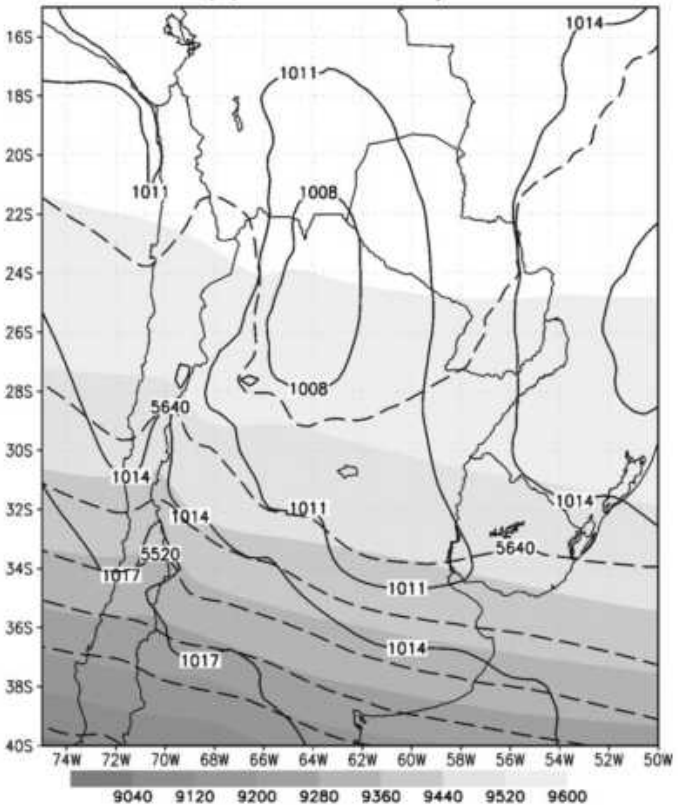

(d) 1200 UTC July 06

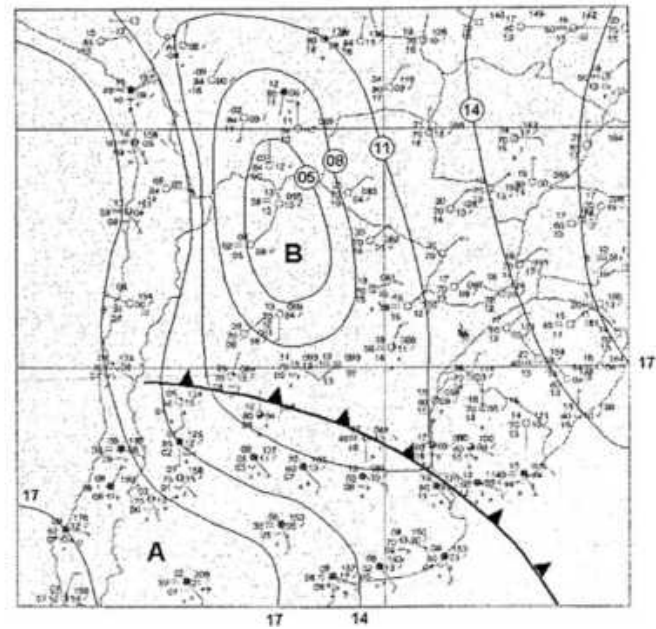

FIG. 4. The 24- and 48-h Eta/CPTEC forecast valid for (a) 1200 UTC 5 Jul and (b) 1200 UTC 6 Jul (sea level pressure in solid lines and 500-1000-hPa thickness in dashed lines). Also shown are manual analyses at (c) 1200 UTC $5 \mathrm{Jul}$ and (d) 1200 UTC 6 Jul. Isobar intervals are $3 \mathrm{hPa}$, and symbols used have their usual meaning.

height curves, which, taken together, show a strong relationship between the thermal field and the surface pressure tendency. On the other hand, 600- and 300$\mathrm{hPa}$ surfaces behave similarly, with a slight negative tendency during the first $36 \mathrm{~h}$. Provided that the life cycle of the NAL closely follows thickness behavior, with upper-level disturbances influencing low pressure variability to a lesser extent, the thermal character of this system can then be inferred. To better support this assertion, Fig. 8 shows the temperature and geopotential height difference during the deepening (0900 UTC 25 February-2100 UTC 26 February) and the decay (2100

$\leftarrow$

FIG. 3. Forecasted fields obtained by the Eta/CPTEC valid for (a) 2100 UTC 25 Feb (21-h forecast), (b) 1200 UTC 26 Feb (36-h forecast), (c) 2100 UTC 26 Feb (45-h forecast), and (d) 1200 UTC 27 Feb (60-h forecast). Contours are the same as in Fig. 2. Also shown are the manual analyses corresponding to (e) 1200 UTC 26 Feb and (f) 1200 UTC 27 Feb. Isobars intervals are 3 hPa, and symbols used have their usual meaning. 
(a)

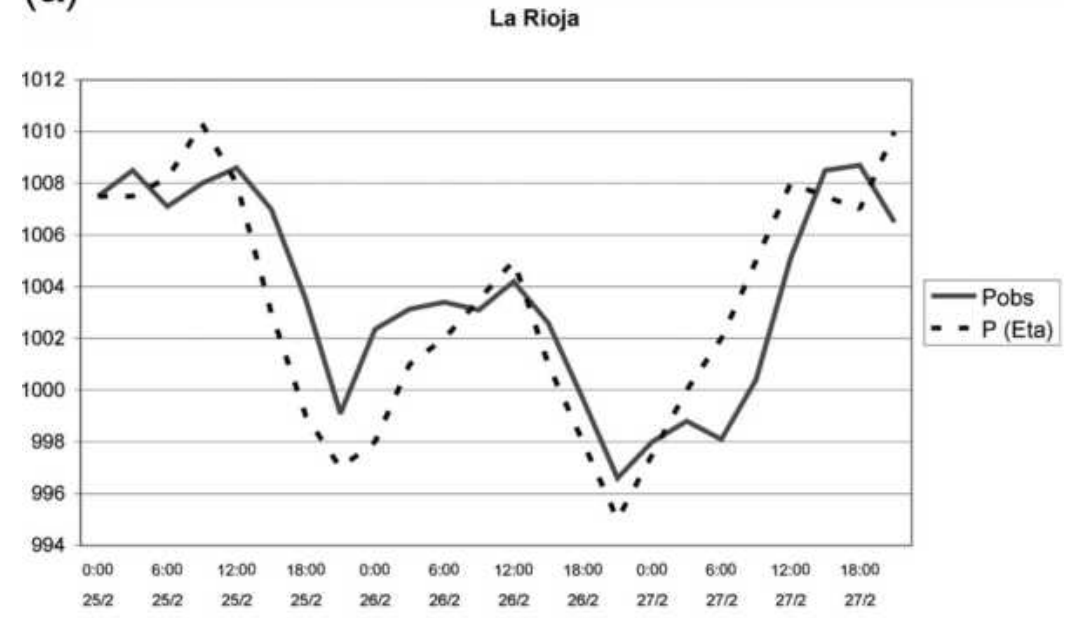

(b)

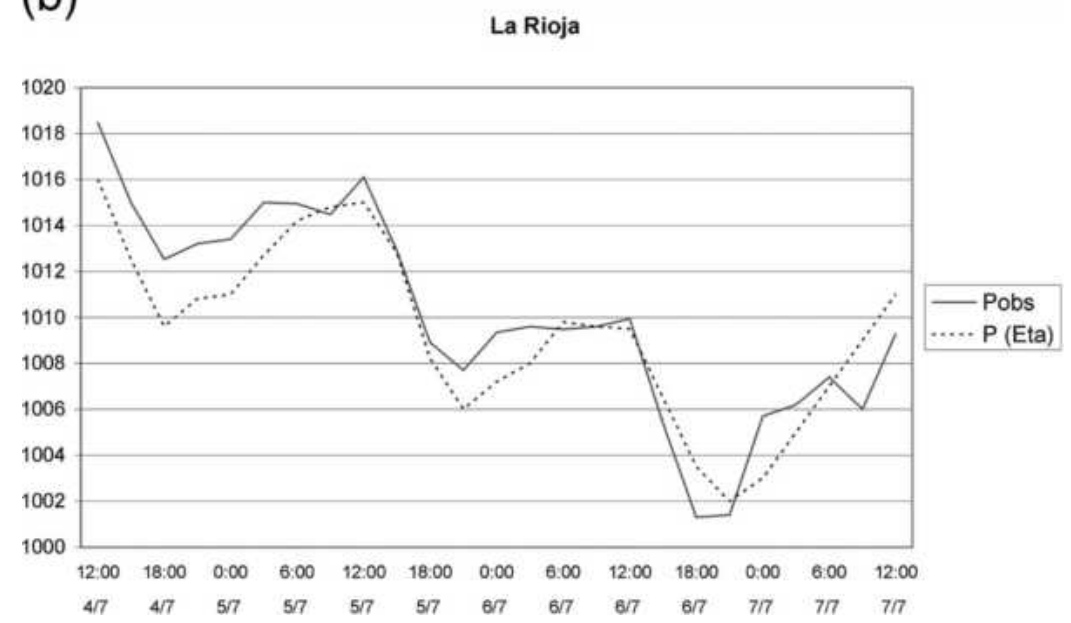

FIG. 5. Temporal evolution of observed (solid lines) and forecasted (Eta/CPTEC, dashed lines) sea level pressure at the La Rioja station (near the NAL center) for the (a) summer and (b) winter cases.

UTC 26 February-1500 UTC 27 February) stages, respectively, at $30^{\circ} \mathrm{S}$. During the former stage, more pronounced temperature increases and geopotential falls are primarily restricted to the middle-lower troposphere near the eastern Andean slope. On the contrary, levels between 300 and $600 \mathrm{hPa}$ have a weak temperature change and a quasi-uniform height fall, in agreement with Fig. 7. During the decay stage this property is still more remarkable since stronger temperature and geopotential variations are confined under the $500-\mathrm{hPa}$ level. As a consequence, during most of the NAL's life cycle, variations of geopotential heights at $900 \mathrm{hPa}$ are basically determined by the $600-900-\mathrm{hPa}$ thickness perturbations, although upper-level forcing cannot be completely ignored. This behavior yields the characterization of the NAL as a thermal system.

In the 6 July 2000 situation the NAL displayed a temporal evolution similar to that depicted in Fig. 3.
Figure 9 reveals that in this case the low pressure center exhibited a sustained deepening and a weaker diurnal cycle compared to the summer event. Thickness variability is still opposite to that in the $900-\mathrm{hPa}$ geopotential height, suggesting that, even during winter, the thermal signature is present. A difference with respect to the 26 February case is that a systematic geopotential decrease is observed at middle and upper levels during the intensification period. Nevertheless, the relative 300-600-hPa thickness still remains unchanged, indicating that the NAL life cycle is basically driven by the 600-900-hPa thickness behavior plus the additional effect of the 600-hPa geopotential fall. An analysis such as the one performed in Fig. 8, but for this event (not included), displays a similar pattern, except for geopotential tendencies in the upper troposphere that are comparatively larger in the winter event.

It should be noted that these systems do not fit into 
(a) 30 S 2100 UTC FEB 26

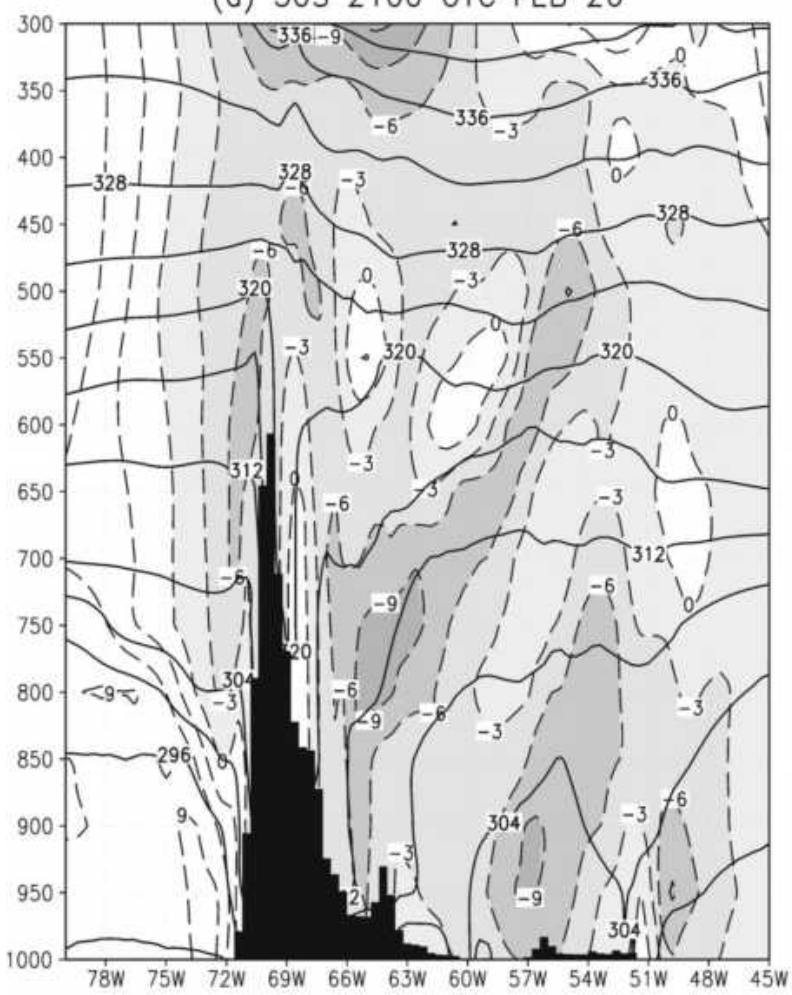

(b) $66 \mathrm{~W} 2100$ UTC FEB 26

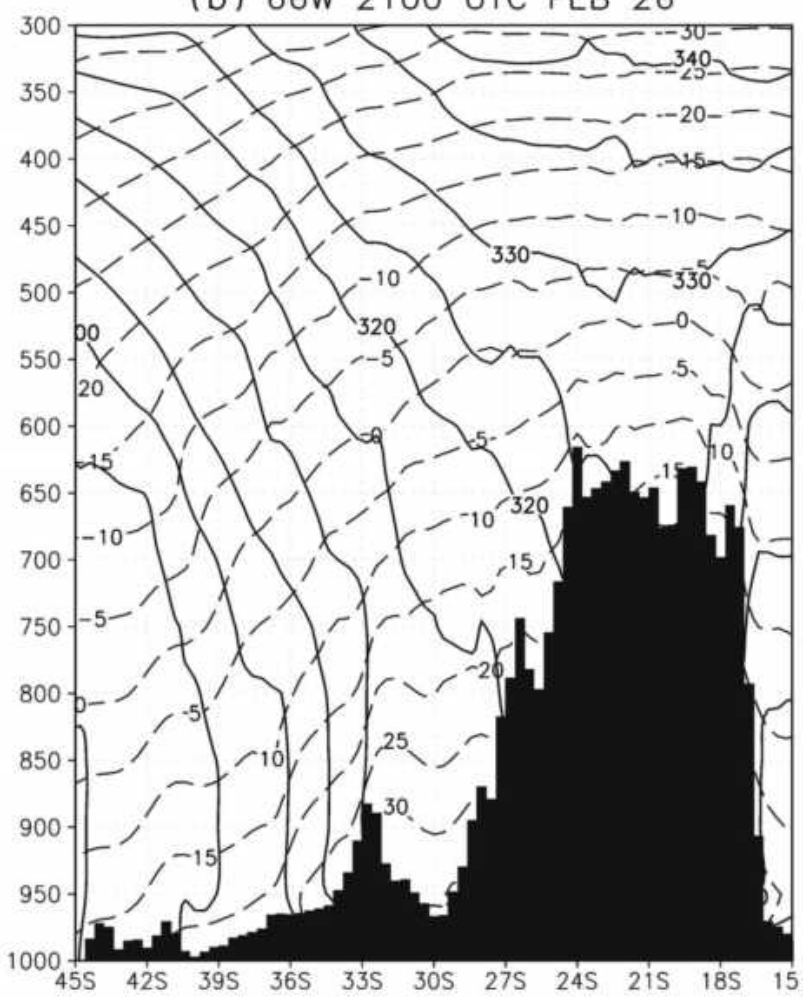

FIG. 6. Vertical cross sections (45-h Eta/CPTEC forecasts) at (a) $30^{\circ} \mathrm{S}$ [meridional wind ( $\mathrm{m} \mathrm{s}^{-1}$ ) in dashed lines, negative values are shaded, and potential temperature $(\mathrm{K})$ in solid lines] and (b) $66^{\circ} \mathrm{W}$ [temperature $\left({ }^{\circ} \mathrm{C}\right)$ in dashed lines and potential temperature $(\mathrm{K})$ in solid lines]. Model topography is indicated.

the classical definition of thermal systems, since they do not exhibit an upper-level anticyclonic circulation. Nevertheless, we still refer to them as "thermal" given that the significant portion of their variability can be explained by changes in temperature at lower levels. This is particularly evident in the summer case, while in winter, the upper-level dynamical component becomes more relevant and cannot be disregarded.

\section{Physical mechanisms involved in the life cycle of the NAL}

\section{a. Mean vertically integrated structure of the temperature tendency field}

The previous section introduced the thermal nature of the NAL events reported in this paper, in agreement with what had previously been found by L80. In what follows, and supported by the hypothesis that the NAL owes many of its features to low-level temperature changes, the thermal field trend will be analyzed, based on the description of each term acting upon the temperature tendency equation presented in section 3 . To describe the NAL evolution, each term contribution has been vertically integrated from the surface up to approximately the $600-\mathrm{hPa}$ level, that is, the layer where thermal effects are concentrated.
Figure 10 depicts these contributions during the intensification period of the summer case. This period is defined as between 0900 UTC 25 February and 2100 UTC 26 February. Focusing on the box collocated with the NAL, there are two processes that mainly account for its deepening: warming by latent heat release (see moist processes contribution in Fig. 10c) and surface sensible heat transport (Fig. 10e) that leads to enhanced surface warming over relatively dry areas. Looking at the static stability pattern (Fig. 10b), it can be seen that cooling resulting from upward motion counteracts much of the warming produced by moisture processes over this particular region (Fig. 10c). As could be expected, the radiation balance over the atmosphere (Fig. 10d) is negative over the whole domain. The horizontal advection (Fig. 10a) depicts a positive contribution east of $63^{\circ} \mathrm{W}$ that explains most of the warming pattern over this region (see Fig. 10f). This effect is associated with the enhanced northerly winds east of the NAL where a Chaco low-level jet has also been detected (Nicolini and Saulo 2000). Nevertheless, over the NAL the horizontal thermal advection is predominantly cold. This fact is in disagreement with Lichtenstein's previous findings, which suggested that warm horizontal advection was a key mechanism leading to NAL development.

The overall aspect of the temperature trend (Fig. 10f) 


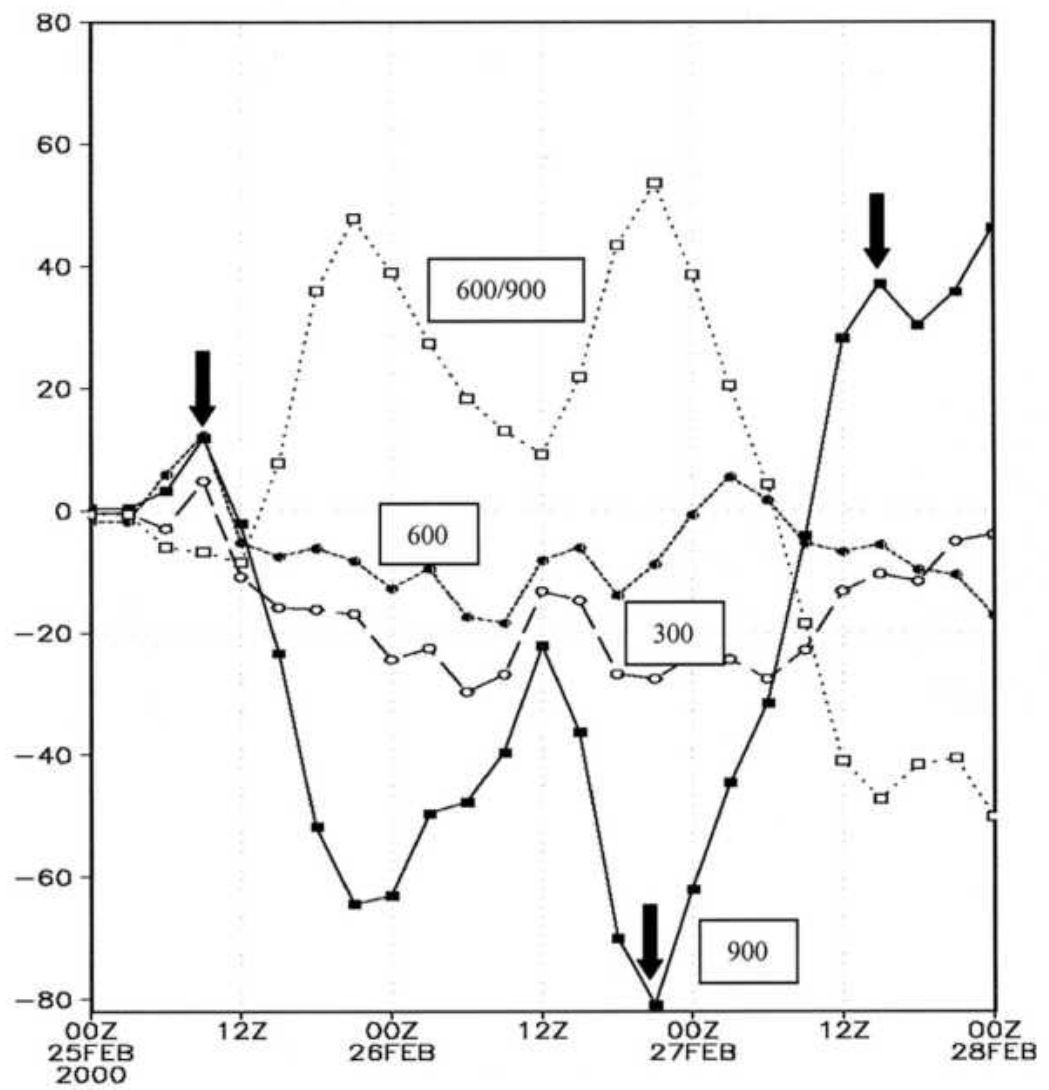

FIG. 7. Temporal evolution of forecasted 600-900-hPa thickness (dotted line with open squares) and geopotential height at the $600-\mathrm{hPa}$ (dotted line with solid circles), $300-\mathrm{hPa}$ (dashed line with open circles), and 900-hPa (solid line with solid squares) levels. Magnitudes (in gpm) are relative to a reference value for each level/variable. Dark arrows indicate the beginning of the intensification period, the maximum NAL intensity/beginning of the decaying phase, and the end of the decaying period, respectively.

is characterized by two main warm areas, one collocated with the NAL and strongly dominated by surface heating and another over northern Argentina, linked to warm horizontal advection. The contrast in the temperature tendency field across $32^{\circ} \mathrm{S}$ may be related to the frontal system described in section 3 . It should be noted that the pattern depicted in Fig. 10f closely resembles the 600-900-hPa thickness tendency for the same period (figure not included).

The decay period is illustrated by Fig. 11, that describes the evolution of the NAL between 2100 UTC 26 February and 1200 UTC 27 February. The most relevant feature arising from this figure is the negative contribution of almost all the terms. The only exception is heating by moisture processes over the NAL (Fig. 11c) that, as in the previous stage, is counteracted by the static stability term. The contribution of precipitation processes is reasonably well correlated with the observed accumulated precipitation between 1200 UTC 26 February and 1200 UTC 27 February (figure not shown). Warm advection still remains important over northeastern Argentina (Fig. 11a). Well-organized cold advection is detected close to the Andes and at midlatitudes, denoting the frontal passage. Surface processes are now less important, being dominated by nocturnal cooling. As a whole, most of the domain is undergoing cooling (mainly due to cold advection), but this effect is enhanced over the NAL.

Figures 12 and 13 correspond to the 6 July 2000 NAL case intensification and decay periods, respectively. Compared with the summer episode it now appears that warming by subsidence in the lee of the Andes (Fig. $12 \mathrm{~b}$ ) is the main mechanism that explains the NAL development, with a negligible influence of moisture processes. If diabatic heating (other than that provided by moisture processes) is thought of as a sum between "radiation" and sensible heat transport from the surface (i.e., "surface processes"), then its role is less significant than in the 26 February case. Figure $12 \mathrm{f}$ shows a similar pattern to that found in the summer case but with a weaker magnitude. The decay of this system can now be mainly explained by a reversal in the static stability term (Fig. 13b) that becomes negative in the area of interest. The synoptic-scale pattern is associated 
(a) Intensification

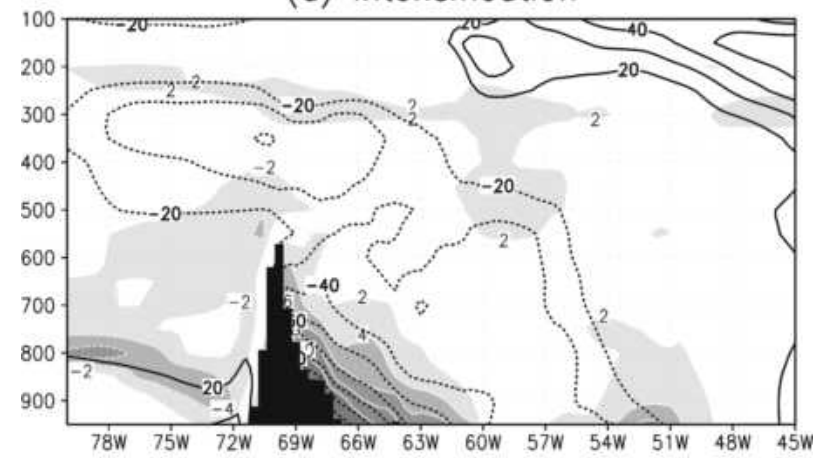

(b) Decay

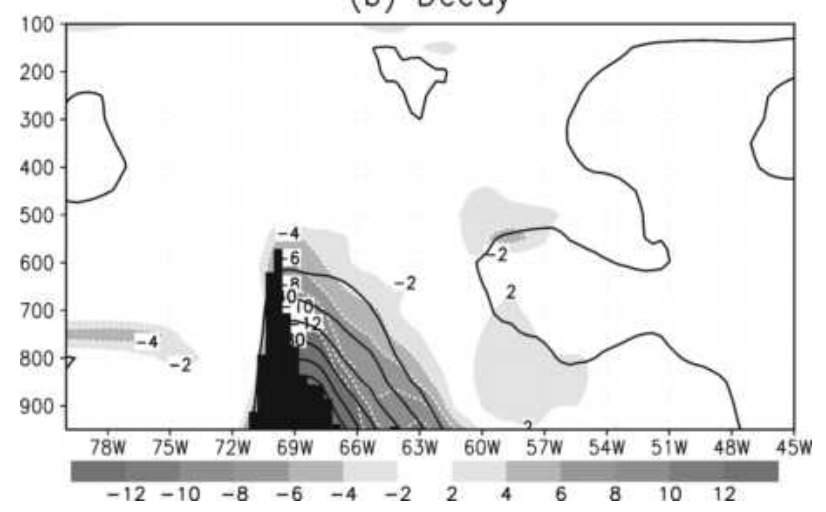

FIG. 8. Vertical cross section at $30^{\circ} \mathrm{S}$ of geopotential height (mgp, solid lines) and temperature $\left({ }^{\circ} \mathrm{C}\right.$, shaded) change during the (a) intensification period and (b) decay phase for the summer case. Model topography is included.

with upward motion forced by the cold front passage. Heat lost by radiation is also significant, since this interval corresponds to nocturnal hours (Figs. 13d, 13e).

To further illustrate the role of subsidence upon the winter-system life cycle, a vertical cross section of mean potential temperature and omega vertical velocity is shown in Fig. 14. During the intensification stage, subsidence in the lee of the Andes appears between 500 and $800 \mathrm{hPa}$, denoting a Foehn effect locally known as Zonda wind (Norte 1988). This downward motion alters most of the 600-900-hPa layer, which in turn has been previously pointed out as the main forcing mechanism responsible for the NAL variability. This Foehn effect is interrupted during the decay phase when large-scale upward motion prevails. While subsidence warming did not appear to be an important mechanism for NAL development in the 26 February case, this should not be considered a systematic behavior in summer, since evidence of the Foehn effect has been occasionally found during summer NAL cases (e.g., on 7 January 2000).

\section{b. Vertical and temporal variability of temperature tendency within the NAL}

This subsection is devoted to the analysis of the vertical and temporal structures of each effect upon the

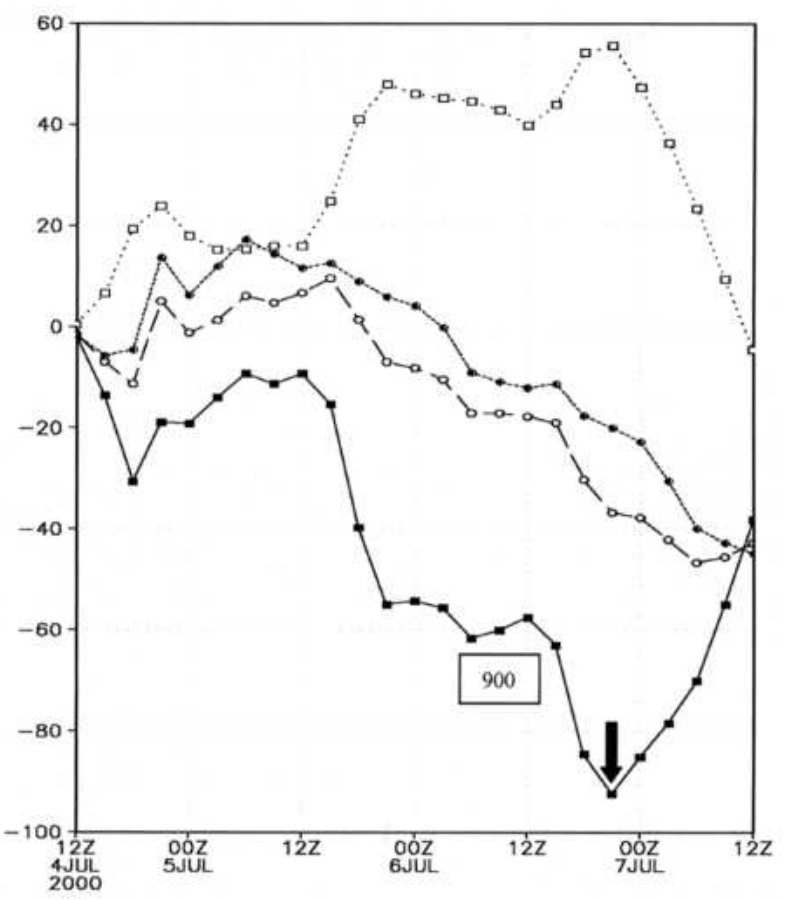

FIG. 9. Same as in Fig. 7, but for the winter case.

accumulated temperature tendency over the box encompassing the NAL (see Fig. 1). An inspection of Fig. 15 confirms that for the summer case, horizontal cold advection dominates the 600-950-hPa layer, with an augmented cooling associated with the frontal passage after 2100 UTC 26 February. This reveals that cold horizontal advection may have acted as one of the principal mechanisms leading to NAL decay. Static stability (Fig. 15b) does not contribute to warming below the $600-\mathrm{hPa}$ level, though there is a localized warming by subsidence centered at $500 \mathrm{hPa}$ (near the top of the Andes), with a diurnal oscillation that maximizes at late afternoon. This is a signature of upper Zonda winds, discussed by Norte (1988). Cooling by adiabatic ascent also strengthens after 2100 UTC 26 February after the frontal passage.

Moisture processes were slightly positive during the intensification period in the lower troposphere, becoming more positive in the decaying stage, though their contribution could not counteract adiabatic cooling. Warming in the 600-950-hPa layer is clearly dominated by the net effect of radiation and surface heating, which exhibits a coherent diurnal oscillation signal and an accumulated warming effect of $5^{\circ} \mathrm{C}$ from 0000 UTC 26 February to 0000 UTC 27 February, and of $2^{\circ} \mathrm{C}$ on the following day. This effect could have explained per se a hydrostatic thickness rise of around 140 geopotential meters (gpm) and the associated sea level pressure fall if the thickness above remained unchanged.

In the 6 July 2000 episode (Fig. 16) neither horizontal advection nor moisture processes added to a positive temperature tendency. Radiation and surface processes 
(a) Horiz Adv.

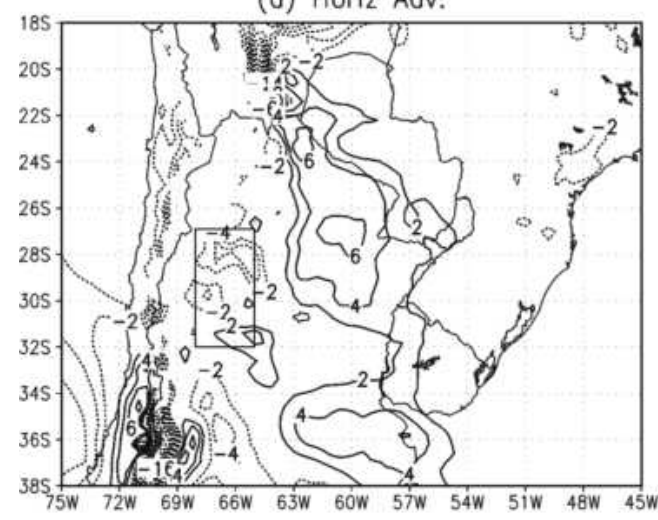

(c) Moist. Proc.

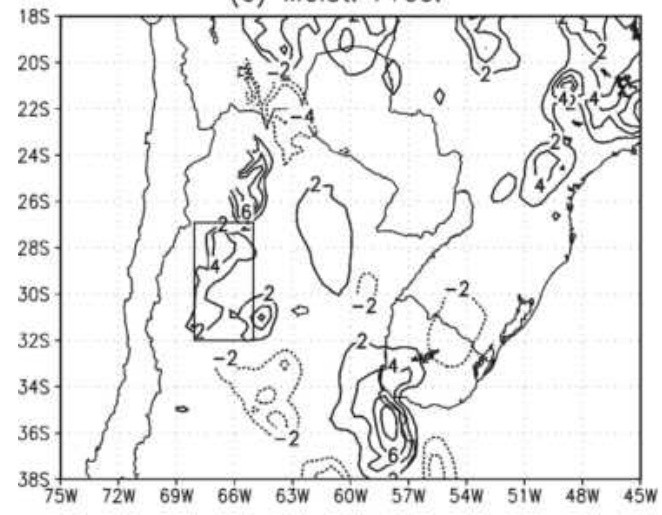

(e) Surface Proc.

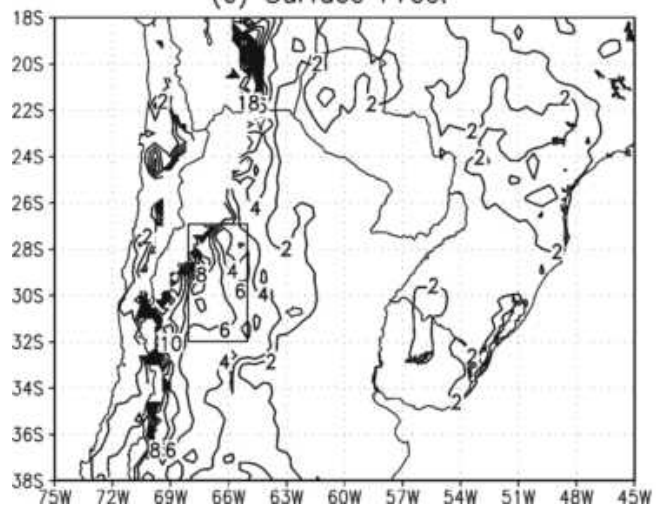

(b) Static Stab.

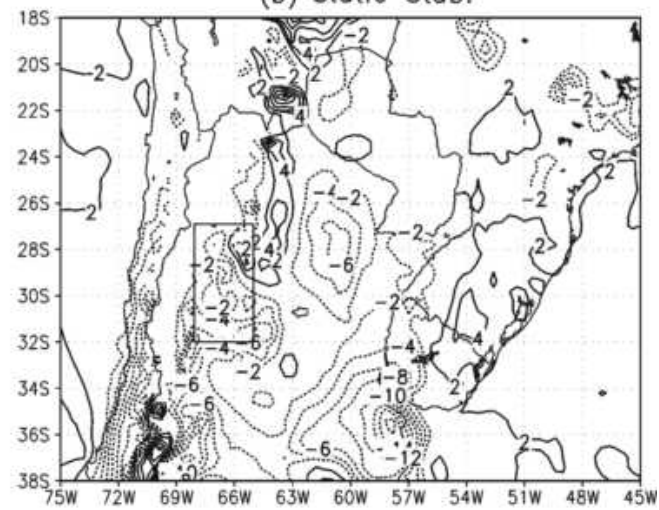

(d) Radiation

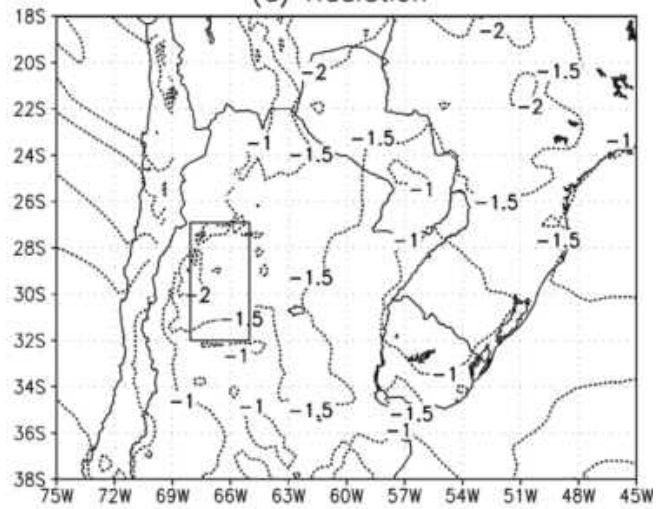

(f) All

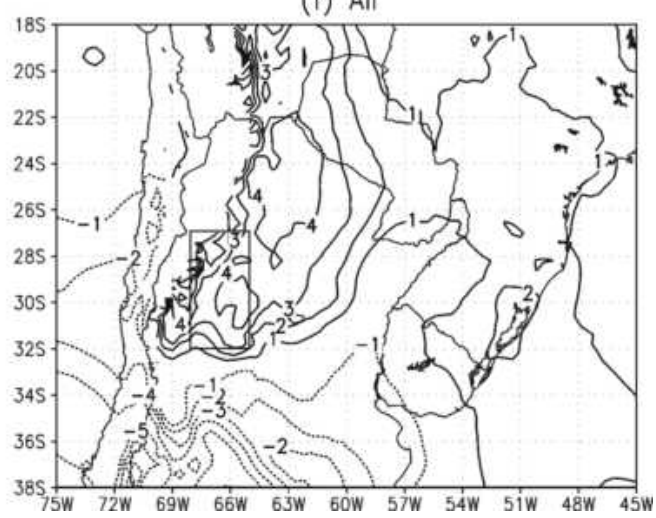

FIG. 10. Temperature change $\left({ }^{\circ} \mathrm{C}\right.$; averaged between the surface and $600-\mathrm{hPa}$ levels) extracted from the terms of the thermodynamic equation in $\eta$ coordinates (Eta/CPTEC forecast) during the intensification period $(36 \mathrm{~h})$ of the summer case. Panels correspond to the partial contribution of (a) horizontal advection, (b) static stability, (c) moisture processes, (d) radiation, and (e) surface processes. (f) The temperature tendency obtained as a sum of all the partial contributions [(a)-(e)]. Values where topography is higher than $1500 \mathrm{~m}$ were masked. The open square represents the region encompassed by the NAL (as in Fig. 1).

(Fig. 16d) now generate a weak gain constrained to a shallower layer while the $600-800-\mathrm{hPa}$ layer is undergoing cooling because of these contributions. The unique processes leading to a net warming between 600 and $900 \mathrm{hPa}$ are vertical displacements, which achieve maximum intensity just before the NAL attained its min- imum pressure. A strong and persistent Zonda effect is now detected.

\section{c. Position of the NAL}

In order to study in more detail the causes that determine the position of the NAL, we analyzed the be- 
(a) Horiz Adv.

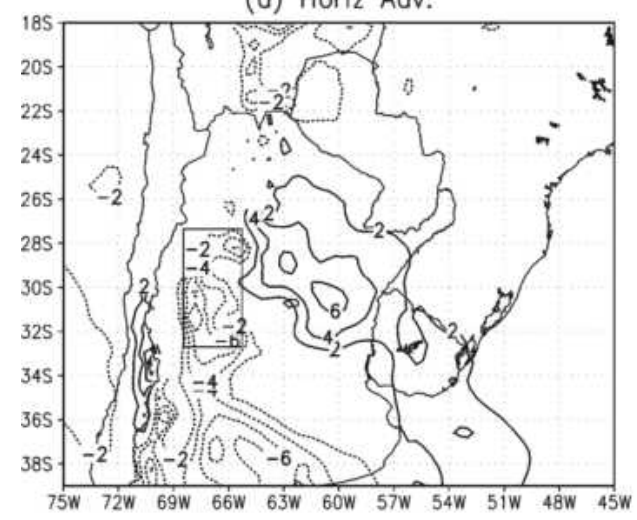

(c) Moist. Proc.

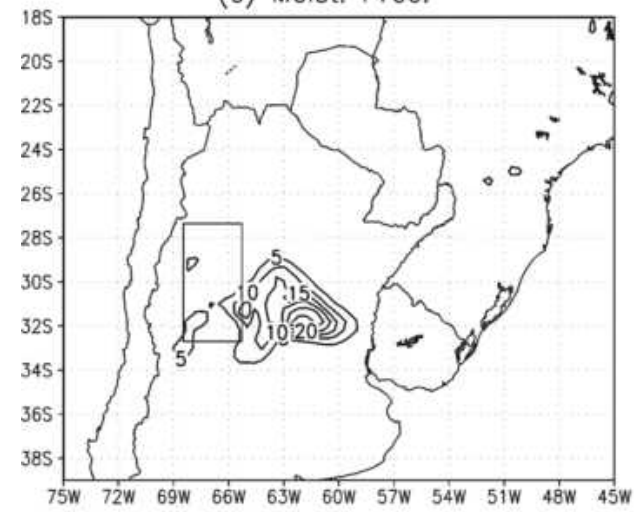

(e) Surface Proc.

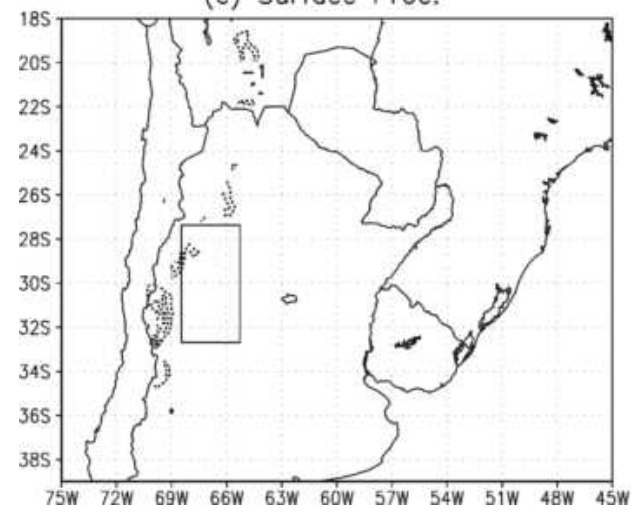

(b) Static Stab.

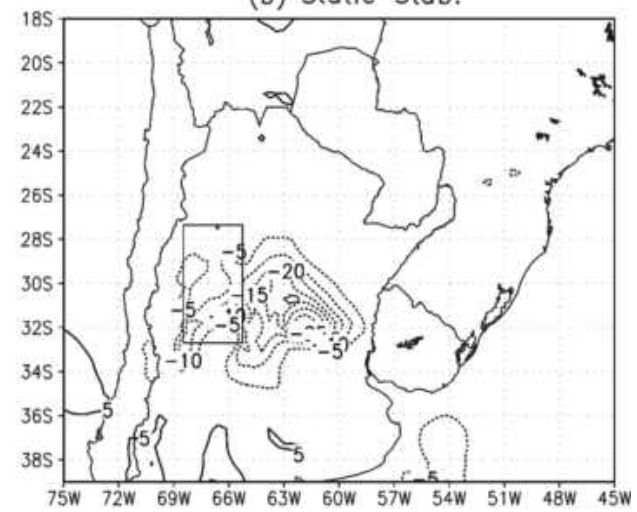

(d) Radiation

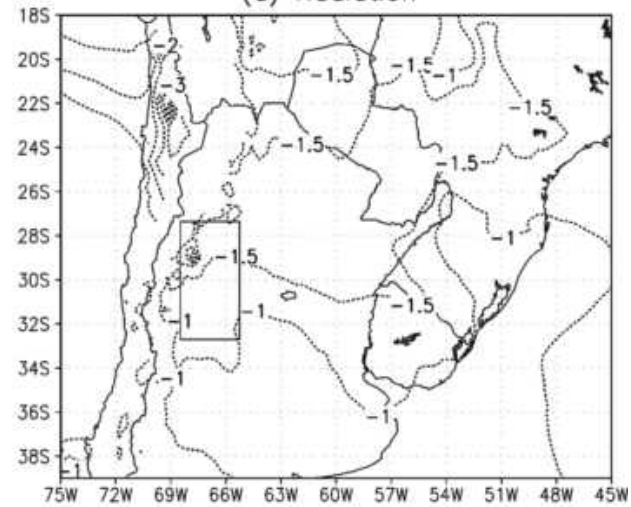

(f) All

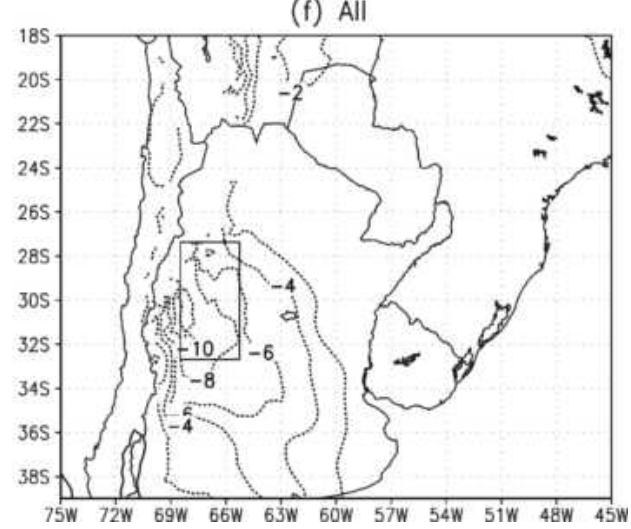

FIG. 11. Same as in Fig. 10, but for the decaying period (2100 UTC 26 Feb-1500 UTC 27 Feb).

havior of the 600-900 hPa thickness, the geopotential height at 900-, 600-, and 300-hPa levels, and each one of the examined physical processes in three boxes located immediately to the north, south, and east of the NAL (see Fig. 1 for boxes' locations; figures are not included). In the analyzed cases, a depression is formed almost with the same intensity in the northern box, since the NAL has an elongated shape. The slightly weaker intensity of the low pressure system in the northern box arises from the lesser positive contribution of the static stability and/or from a lesser geopotential height fall in the middle troposphere. This feature could indicate a weaker dynamical component possibly due to the lower latitude of the box. Inside the eastern box the horizontal advection is substantially positive. Nevertheless, a negative (or less positive) static stability contribution and a considerably smaller surface heating compensate this process. This latter fact is associated with the significant 
(a) Horiz Adv.

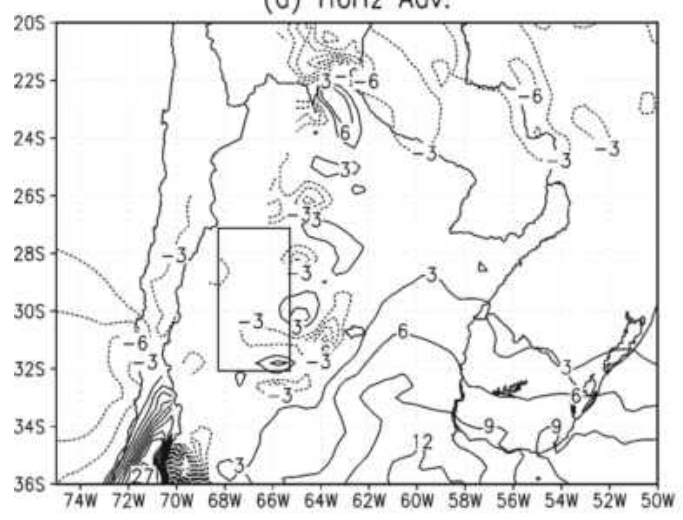

(c) Moist. Proc.

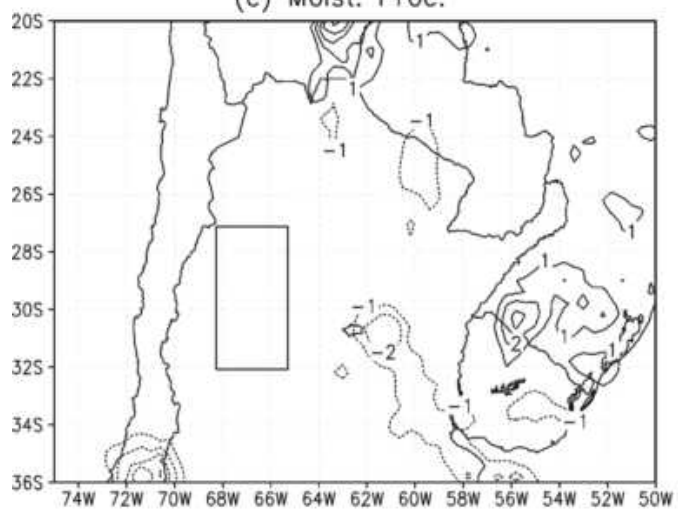

(e) Surface Proc.

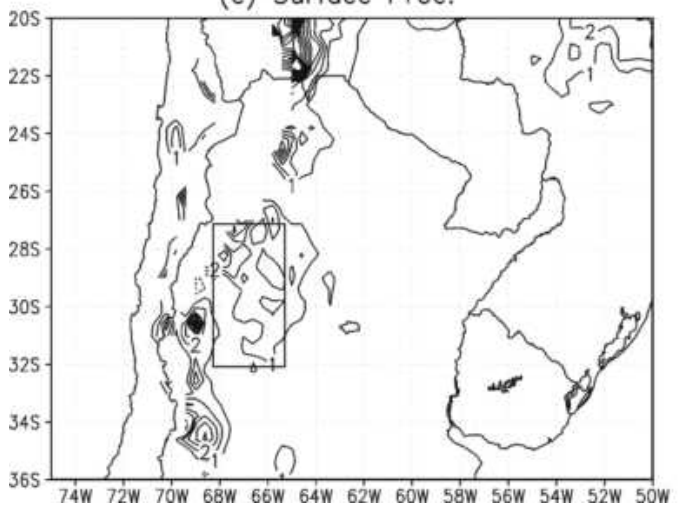

(b) Static Stab.

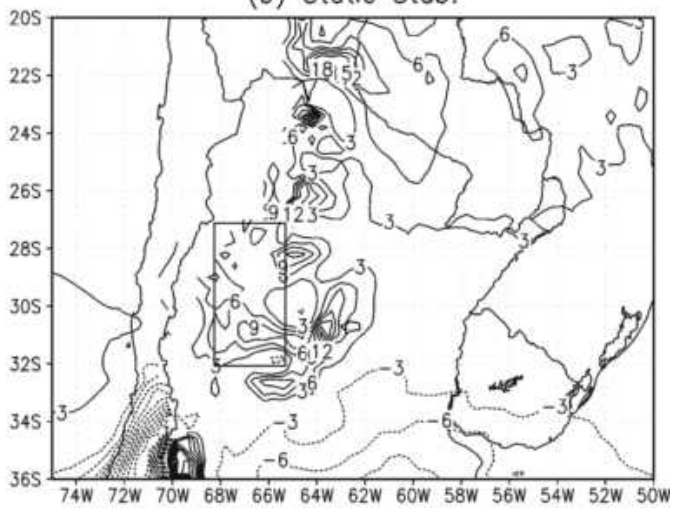

(d) Rodiation

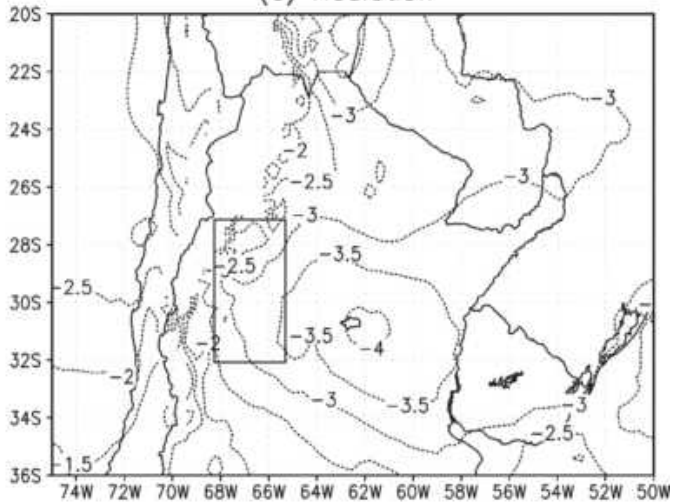

(f) All

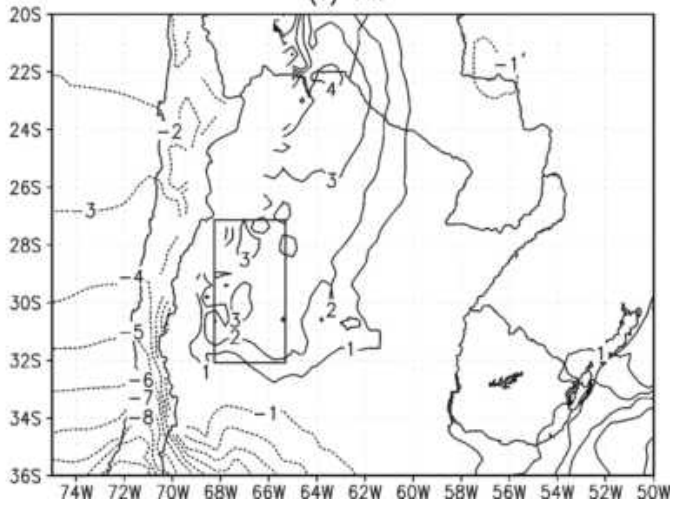

FIG. 12. Same as in Fig. 10, but for the intensification period of the winter case (1200 UTC 5 Jul-2100 UTC 6 Jul).

zonal gradient of sensible and latent heat flow diagnosed by the model around $65^{\circ} \mathrm{W}$, which is coherent with the soil moisture climatology. The low pressure system appears weaker and distorted in the southern box. In general, the thermal component (thickness increase) is not so evident (except in the case of 6 July where the Zonda wind blew) and the rate of surface warming is considerably reduced compared to the one observed directly over the NAL box. Another important difference is that moist processes were negligible in this subregion.

\section{Concluding remarks}

This study focuses on the description of two northwestern Argentinean low (NAL) episodes, one for summer and the other one for winter, that were selected following Lichtenstein (1980) criteria. According to L80, these kind of systems are characterized by a thermal orographic origin, being more frequent in summer and highly intermittent in winter. With the aid of a highresolution regional model (Eta/CPTEC) the main mech- 
(a) Horiz Adv.

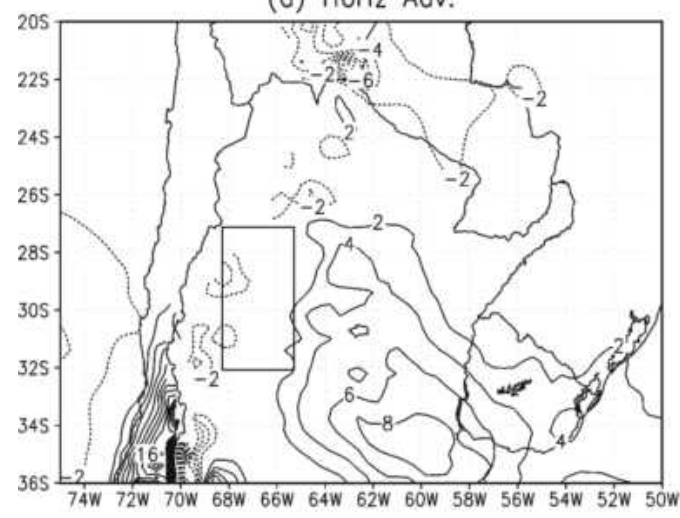

(c) Moist. Proc.

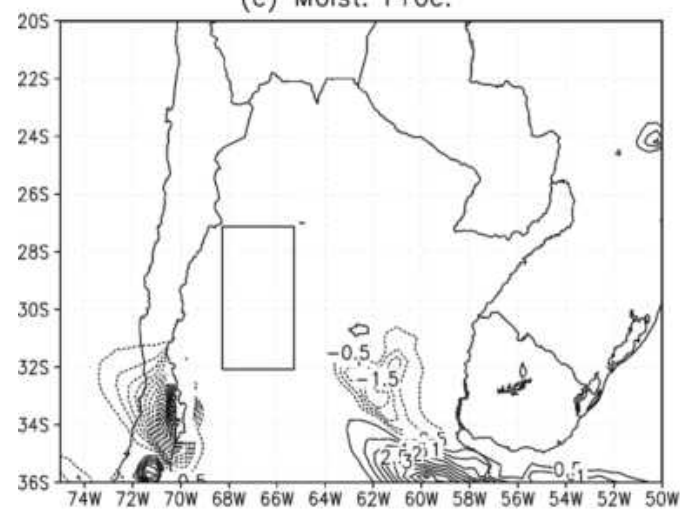

(e) Surface Proc.

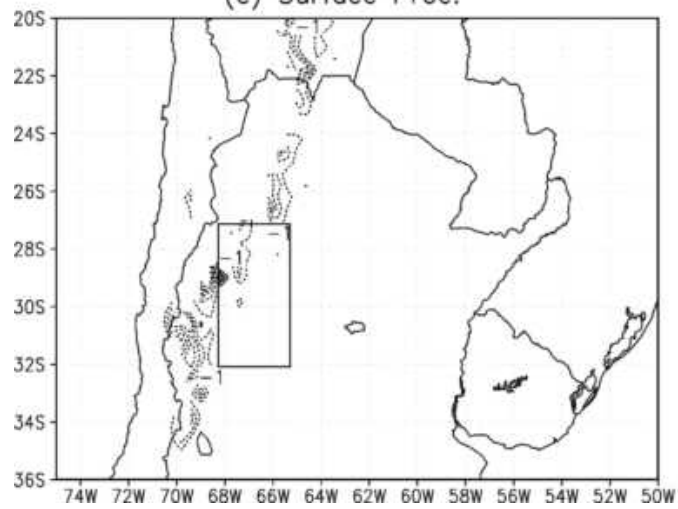

(b) Static Stab.

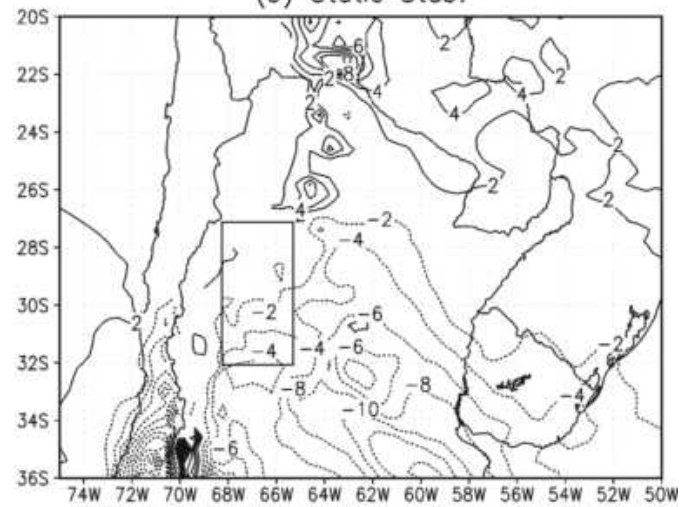

(d) Rodiation

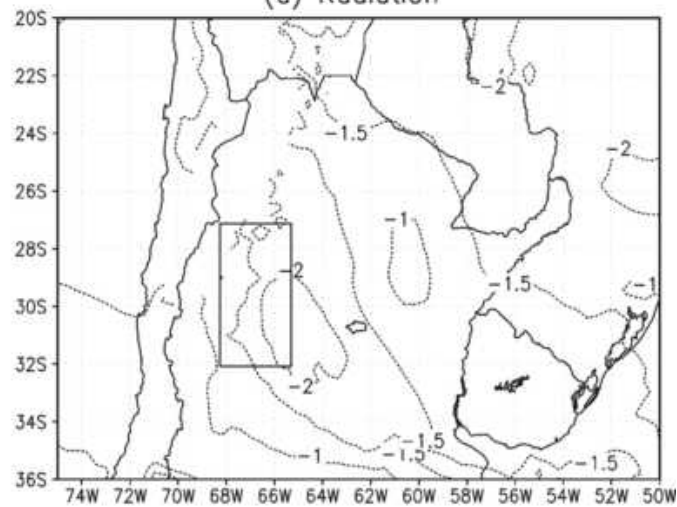

(f) All

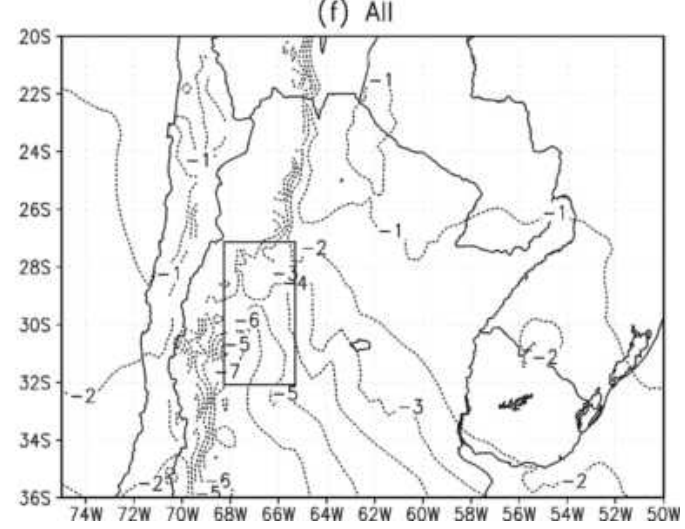

FIG. 13. Same as in Fig. 12, but for the decaying period of the winter case (2100 UTC 6 Jul-1200 UTC 7 Jul).

anisms involved in the NAL life cycle were studied in order to examine how these thermal topographical processes influenced the system behavior, placing special emphasis on the description of its diurnal oscillations and three-dimensional structure. This strategy was adopted since there are presently no observational datasets adequate for this kind of study. In particular, since no radiosoundings are launched at the region of interest, the three-dimensional structure of the NAL could not have been analyzed. Also, taking into consideration the distinct geography of the area, it could be expected that available analyzed fields (i.e., NCEP reanalyses, among others) could not provide a detailed structure of the examined patterns. The Eta/CPTEC outputs were used since they proved to adequately represent the thermodynamical changes undergone by these systems and allowed a detailed description of each process acting upon the temperature field.

The summer NAL surface pressure changes are clearly dominated by the $600-900-\mathrm{hPa}$ thickness variability. 
0600 UTC July 5 to 2100 UTC July 06

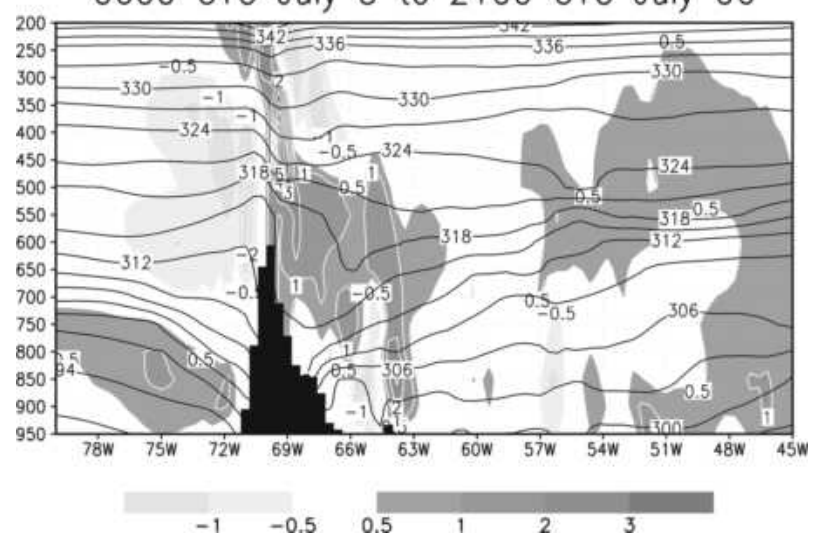

FIG. 14. Vertical cross section of potential temperature (K, solid lines) and omega (hPa seg ${ }^{-1}$, shaded) averaged between 0600 UTC $5 \mathrm{Jul}$ and $2100 \mathrm{UTC} 6 \mathrm{Jul}$, performed at $31^{\circ} \mathrm{S}$. Model topography is indicated.
In winter, this effect is reinforced by the 600-hPa geopotential height fall associated with an upper-level trough approach. The modulation of NAL pressure oscillations by thickness variability strongly suggests the thermal character of these systems. Based on this result, the temperature tendency equation has been used to quantify all the contributions to thermal changes.

The 26 February event has been found to be dominated by surface warming. This single mechanism could have explained the low pressure system formation by itself. This finding suggests that, during summer, the NAL could always be present over the region where a maximum positive net radiative balance is attained, unless an adverse process would destroy this positive balance. This had already been pointed out by L80, though he could not completely explain the climatological NAL intensity by surface radiative warming alone. The other mechanism suggested by L80 to explain observed NAL depth was thermal horizontal warm advection. This effect was not found in our case studies. What has been
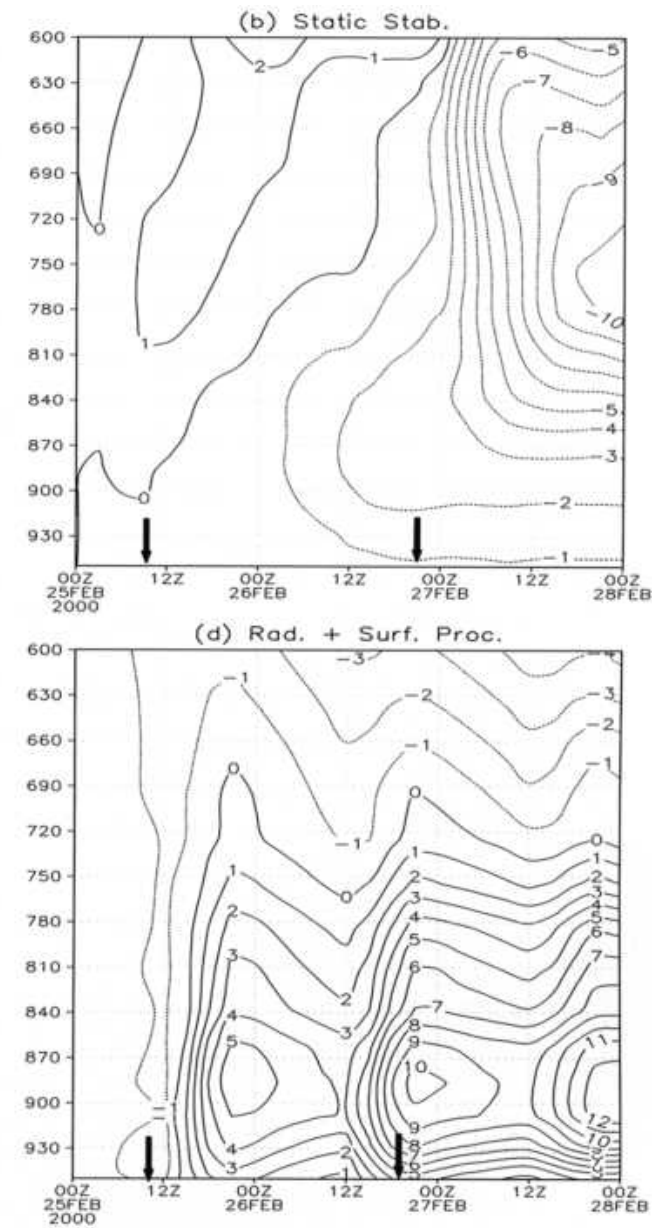

FIG. 15. Time-pressure sections of 3-hourly temperature tendency (values in ${ }^{\circ} \mathrm{C}$ are accumulated from 0000 UTC 25 February) extracted from the thermodynamic equation (Eta/CPTEC) for the summer case. Panels correspond to the partial contribution of (a) horizontal advection, (b) static stability, (c) moisture processes, and (d) radiation and surface processes. Dark arrows indicate the beginning of the intensification period and the max NAL intensity/ beginning of the decaying phase, respectively. 

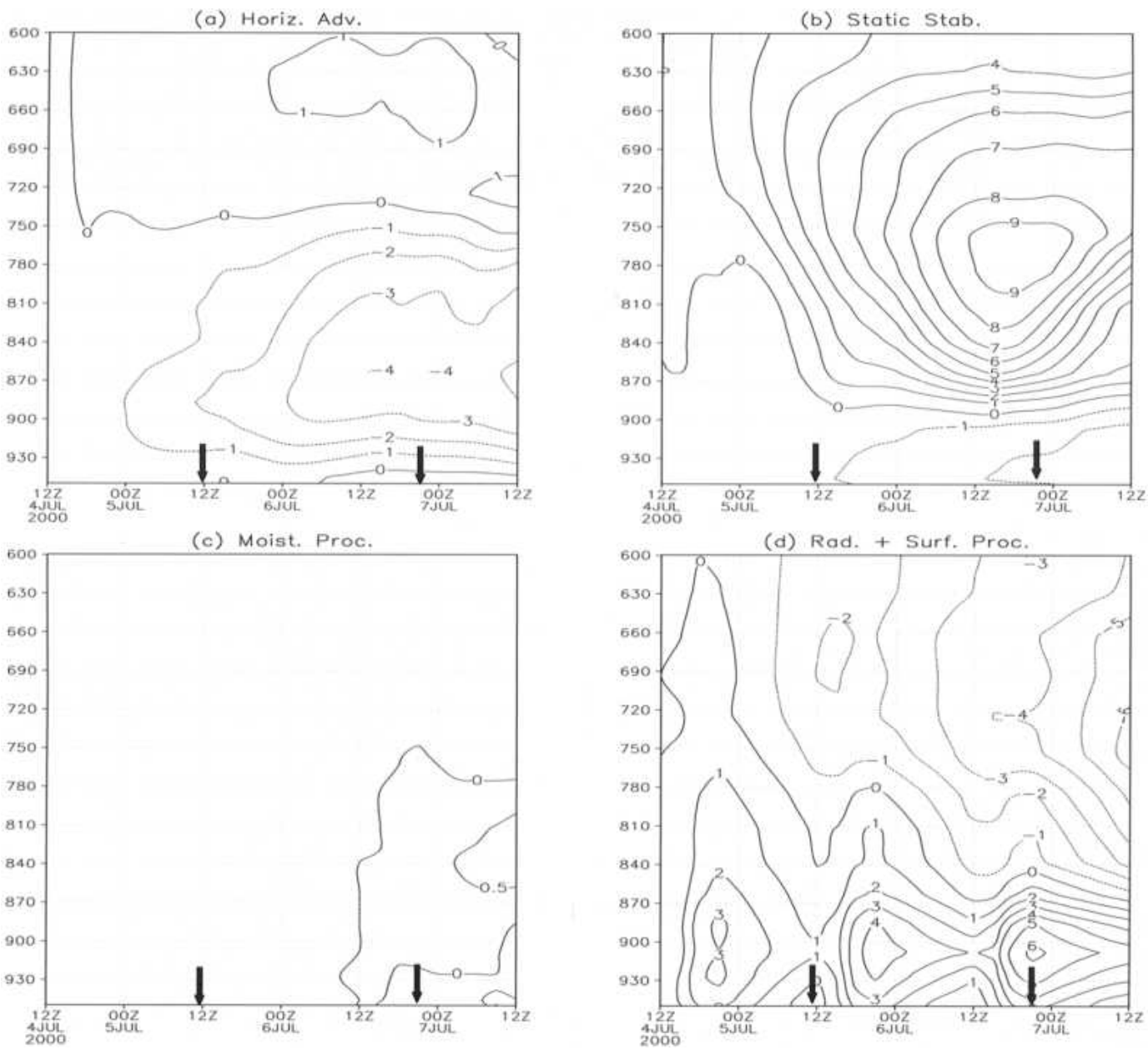

FIG. 16. Same as in Fig. 15, but for the winter case.

found in the analyzed cases is the positive role played by a Foehn effect (warming by subsidence) and/or by latent heat release. In the summer case, the "intermittent" behavior of the NAL is associated with a suppression of the net warming in the 600-900-hPa layer due to a cold air surge.

In winter, the surface + radiative heat balance in the 600-900-hPa layer is weakly negative and cannot explain the NAL formation. Again, L80 suggested thermal horizontal warm advection as the principal forcing mechanism for NAL formation during this season. In the winter case studied here, however, the Zonda effect was the main process responsible for NAL development. This effect arises in connection with an upper-level cyclonic disturbance approaching the Andes, indicating that, in this case, the "thermal response" is triggered by a dynamical forcing. Since Zonda winds are a frequent winter phenomenon associated with frontal activity (Norte 1988) this factor could be thought of as a primary mechanism leading to winter NAL. As a consequence, the NAL intermittence in winter could be related to transient baroclinic activity, which now modulates both the intensification and the decay stages.

In reference to L80 hypothesis about the role played by horizontal warm advection, it has been found that warm advection has been present in both cases, but to the northeast of the NAL. This feature seems to be more a consequence of an enhanced pressure gradient that geostrophically accelerates northerly winds than a cause of pressure falls in the NAL. Nevertheless, this interaction should be better analyzed in future works.

A significant diurnal cycle was found in both winter and summer events. The NAL intensifies during daytime hours, reaching its maximum depth at 1800 LST. This oscillation closely follows the heat balance at the surface, as expected. The NAL has been regarded as a thermal orographic system. This study suggests that the NALs analyzed behave as almost "pure" thermally driven surface lows in summer, while dynamical orographic forcing is the organizing mechanism in winter.

Acknowledgments. The authors wish to thank Dr. Chou Sin Chan for her encouragement. This work was 
partially funded by the Ministry of Science and Technology of Brazil through the PROSUL Program, by the Fundação de Amparo à Pesquisa do Estado de São Paulo (FAPESP), by PROSUR, IAI-CRN 055, and by ANPCyT through PICT 07-06671.

\section{REFERENCES}

Alessandro, A. P., 1993: About upper level thermal and height fields over southern South America (in Spanish). Meteorologica, 18, 33-38.

Betts, A. K., and M. J. Miller, 1986: A new convective adjustment scheme. Part II: Single column test using GATE wave, BOMEX, and arctic air-masses data sets. Quart. J. Roy. Meteor. Soc., 112, 1306-1335.

Black, T. L., 1994: NMC Notes: The New NMC mesoscale Eta model: Description and forecast examples. Wea. Forecasting, 9, 256278.

Bluestein, H. B., 1993: Synoptic-Dynamic Meteorology in Midlatitudes. Vol. II, Observations and Theory of Weather Systems, Oxford University Press, 953 pp.

Chen, F., and Coauthors, 1996: Modeling of land surface evaporation by four schemes and comparison with FIFE observations. $J$. Geophys. Res., 101 (D3), 7251-7268.

Chou, S. C., and M. G. A. Justi da Silva, 1999: Objective evaluation of Eta Model precipitation over South America. Climanálise, 14, 46-60. [Available online at http://tucupi.cptec.inpe.br/products/ climanalise/artigos/artcien2.shtml.]

Fels, S. B., and M. D. Schwarzkopf, 1975: The simplified exchange approximation: A new method for radiative transfer calculations. J. Atmos. Sci., 32, 1475-1488.

Figueroa, S. N., P. Satyamurty, and P. L. Silva Dias, 1995: Simulations of the summer circulation over the South American region with an eta coordinate model. J. Atmos. Sci., 52, 1573-1584.

Gan, M. A., and V. B. Rao, 1994: The influence of the Andes Cordillera on transient disturbances. Mon. Wea. Rev., 122, 11411157.

Garreaud, R., and J. M. Wallace, 1998: Summertime incursions of midlatitude air into subtropical and tropical South America. Mon. Wea. Rev., 126, 2713-2733.

González, M., and V. Barros, 1996: Aspectos estadísticos del ciclo anual de precipitación y sus anomalías en Argentina subtropical. Meteorologica, 21, 15-26.

Hoffmann, J. A., 1975: Climatic Atlas of South America. IOMMUNESCO, printed by Cartographia, $33 \mathrm{pp}$.

Janjic, Z. I., 1979: Forward-backward scheme modified to prevent two-grid-interval noise and its application in sigma coordinate models. Contrib. Atmos. Phys., 52, 69-84.
_ 1994: The new NMC mesoscale Eta model. Description and forecast examples. Wea. Forecasting, 9, 265-278.

Lacis, A. A., and J. E. Hansen, 1974: A parameterization of the absorption of solar radiation in the earth's atmosphere. J. Atmos. Sci., 31, 118-133.

Lenters, J. D., and K. H. Cook, 1997: On the origin of the Bolivian high and related circulation features of the South American climate. J. Atmos. Sci., 54, 656-677.

Lichtenstein, E. R., 1980: La Depresion del Noroeste Argentino (The Northwestern Argentina Low). Ph.D. dissertation, University of Buenos Aires, 223 pp.

Mesinger, F., 1984: A blocking technique for representation of mountains in atmospheric models. Riv. Meteor. Aeronaut., 44, 195202.

— Z Z. I. Janjic, S. Nickovic, and D. Gavrilov, 1988: The stepmountain coordinate: Model description and performance for cases of Alpine lee cyclogenesis and for a case of an Appalachian redevelopment. Mon. Wea. Rev., 116, 1497-1518.

Montecinos, A., A. Díaz, and P. Aceituno, 2000: Seasonal diagnostic and predictability of rainfall in subtropical South America based on tropical Pacific SST. J. Climate, 13, 746-758.

Nicolini, M., and A. C. Saulo, 2000: Eta characterization of the 1997 1998 warm season Chaco jet cases. Preprints, Sixth Int. Conf. on Southern Hemisphere Meteorology and Oceanography, Santiago, Chile, Amer. Meteor. Soc., 330-331.

Norte, F. A., 1988: Características del Viento Zonda en la Región de Cuyo (Zonda wind characteristics over Cuyo-Region). Ph.D. dissertation, University of Buenos Aires, $223 \mathrm{pp}$.

Saulo, C., M. Nicolini, and S. C. Chou, 2000: Model characterization of the South American low-level flow during the 1997-1998 spring-summer season. Climate Dyn., 16, 867-881.

Schwerdtfeger, W. C., 1954: Análisis sinóptico y aspecto climatológico de dos distintos tipos de depresiones báricas en el norte de la Argentina (in Spanish). Meteoros, 4, 301-323.

- 1976: Introduction. Climate of Central and South America, W. Schwerdtfeger and H. E. Landsberg, Eds., World Survey of Climatology, Vol. 12, Elsevier, 7-35.

Seluchi, M. E., and A. C. Saulo, 1998: Possible mechanisms yielding an explosive coastal cyclogenesis over South America: experiments using a limited area model. Aust. Meteor. Mag., 47, 309320 .

__ and J. A. Marengo, 2000: Tropical-midlatitude exchange of air masses during summer and winter in South America: Climatic aspects and examples of intense events. Int. J. Climatol., 20 , 1167-1190.

- and S. C. Chou, 2001: Evaluation of two Eta Model versions for weather forecast over South America. Geofis. Int., 40, 219237.

Zhao, Q., and F. H. Carr, 1997: A prognostic cloud scheme for operational NWP models. Mon. Wea. Rev., 125, 1931-1953. 